Portland State University

PDXScholar

1975

\title{
Location of Dyspraxic Characteristics in Children with Severe "Functional" Articulation Disorders
}

Sara Miller Mitcham

Portland State University

Follow this and additional works at: https://pdxscholar.library.pdx.edu/open_access_etds

Part of the Speech Pathology and Audiology Commons Let us know how access to this document benefits you.

\section{Recommended Citation}

Mitcham, Sara Miller, "Location of Dyspraxic Characteristics in Children with Severe "Functional" Articulation Disorders" (1975). Dissertations and Theses. Paper 2280.

https://doi.org/10.15760/etd.2277

This Thesis is brought to you for free and open access. It has been accepted for inclusion in Dissertations and Theses by an authorized administrator of PDXScholar. Please contact us if we can make this document more accessible: pdxscholar@pdx.edu. 
AN ABSTRACT OF THE THESIS OF Sara Miller Mitcham for the Master of Science in Speech Communication: Emphasis in Speech Pathology/Audiology presented May 27, 1975.

Title: Location of Dyspraxic Characteristics in Children with Severe "Functional" Articulation Disorders

APPROVED BY MEMBERS OF THE THESIS COMMITTEE:

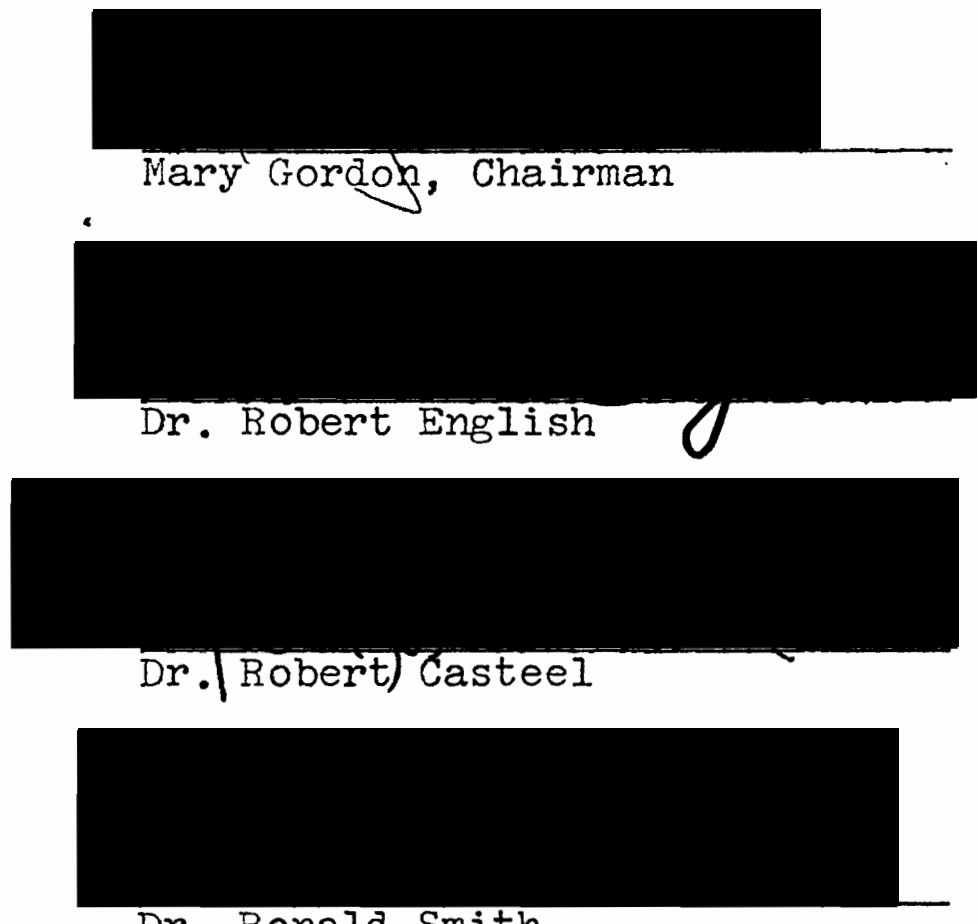

Dr. Ronald Smith

The purpose of this investigation was to determine if children labeled as "severe" functional articulation disordered, who had been enrolled in public school speech programs for one year or more, exhibited dyspraxic-like charac- 
teristics.

Twenty individuals between the ages of 8 and 11 were chosen from the Gresham Public Schools, Lynch Public Schools, Portland Public Schools, Rockwood Public Schools and the Crippled Children's Division, University of Oregon Medical School to serve as subjects for the three groups in this study. Eight subjects who comprised the experimental group were "severe" functional articulation disorders and were selected from the public schools. Each misarticulated four or more phonemes, consistently or inconsistently, in isolation, syllables, words or conversation; each had made little or very slow progress according to his speech clinician and each had been enrolled in speech management for one year or more as a functional articulation case.

Eight subjects in the normal control group were individuals selected from the public schools, with no speech or language problems. Each had never been enrolled in nor recommended for a speech intervention program.

Four subjects in the dyspraxic control group were selected from the University of Oregon Nedical School. Prior to the date of this investigation, each had been diagnosed as displaying developmental dyspraxia, dyspraxia of speech or verbal dyspraxia.

The Modified Apraxia Battery (NAB) utilized in this investigation was a nonstandardized battery consisting of a verbal section and a nonverbal section. The verbal section was composed of ten subtests designed to delineate the pres- 
ence of a dyspraxia of speech; the nonverbal section was composed of one subtest designed to delineate an oral apraxia and one subtest designed to delineate a limb apraxia.

The results of this study revealed a highly significant difference in performance on the verbal section between the normal subjects and the "severe" functional articulation subjects with the normals performing better. A highly significant difference also was found between the normal subjects and the dyspraxic subjects with the normals performing better on the verbal section of the MAB. No significant difference was revealed, however, between the dyspraxics and the "severe" functional articulation cases. It was inferred, therefore, that these two groups performed in a similar manner because they exhibited similar verbal characteristics. "Severe" functional articulation disordered subjects were, therefore, found to exhibit verbal dyspraxic-like characteristics.

No significant difference in performance was shown on the nonverbal section among the three groups.

It appears the verbal section of the Modified Apraxia Battery much more effectively differentiates those displaying dyspraxic-like characteristics from those who do not than does the nonverbal section. Chi square analysis of items on the $M A B$ supported this contention further suggesting subsection 3, Nultisyllabic Words and subsection 6, Sentences are the most discriminating verbal items. 


\title{
IOCATION OF DYSPRAXIC CHARACTERISTICS IN CHILDREN WITH SEVERE "FUNCTIONAL" \\ ARTICULATION DISORDERS
}

\author{
by \\ SARA MILLER MITCHAM
}

\begin{abstract}
A thesis submitted in partial fulfillment of the requirements for the degree of
\end{abstract}

\author{
MASTER OF SCIENCE IN SPEECH COMNUNICATION \\ with an emphasis in \\ SPEECH PATHOLOGY AND AUDIOLOGY
}

Portland State University

1975 
TO THE OFFICE OF GRADUATE STUDIES AND RESEARCH:

The members of the Committee approve the thesis of Sara Miller Mitcham presented May 27, 1975.

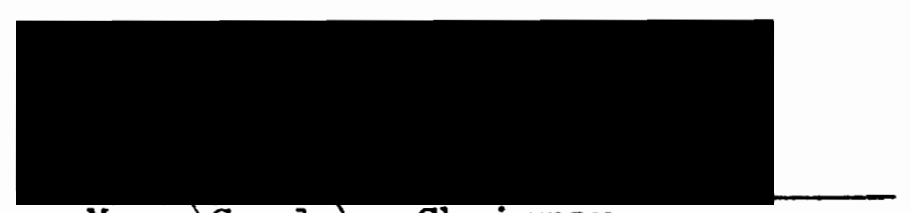

Mary Gordoj, Chairman
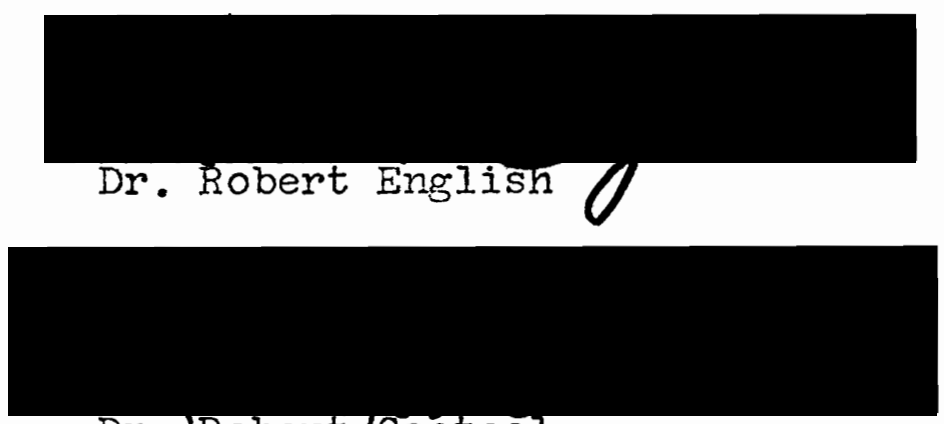

Dr.'Robert'Casteel

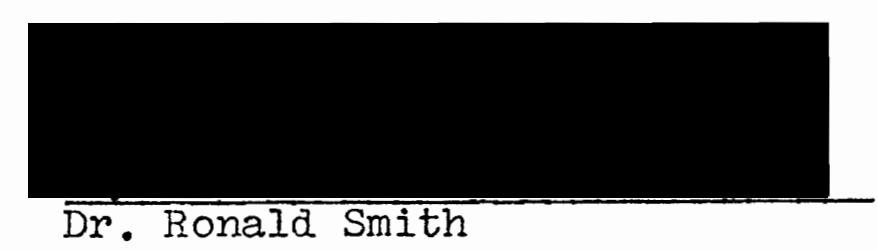

APPROVED :

PJbert W. Vogelfang, Heag(, Department of Speech Communication

Da'vid T. Clark, Dean of Graduate Studies and Research

May 27, 1975 


\section{ACKNOWLEDGNENTS}

I wish to extend my gratitude and sincere appreciation to Mrs. Mary Gordon, the chairman of my thesis committee. Her guidance, her instruction, and her continual cheerfulness made completion of this research study a "possible," rather than an "impossible," task. Thanks also to Dr. Robert Casteel and Dr. Robert English for their most helpful comments and suggestions as members of my committee. A big "thank you!" also to Dr. Ronald Smith for his congenial attitude, his constant availability and his excellent statistical advice.

Finally, I would like to dedicate this thesis to three very special people. First to my parents, who provided unending emotional and financial support through the years and to whom, I gratefully recognize, I owe my education and lastly to Joe who has "put up with me" through this challenging and exacting episode in my life. 
TABLE OF CONTENTS

PAGE

ACKNOWLEDGMENTS . . . . . . . . . . . . . iii IIST OF TABLES . . . . . . . . . . . . . . vii CHAPTER

I INTRODUCTION, STATEMENT OF PURPOSE DEFINITIONS AND LIMITATIONS • • • • • • 1 Introduction . . . . . . . . . . 1

Statement of Purpose ......... 4 Definitions ............ . 4 Apraxia Apraxia Battery Dyspraxia Eupraxia Functional Articulation Disorder Modified Apraxia Battery

Pre-diagnosed Dyspraxia

Severe Functional Articulation Disorder

Limitations . . . . . . . . . 7

Use of Nonstandardized Instrument

Previous Treatment of Pre-diagnosed Dyspraxics

II REVIEW OF THE IITERATURE . . . . . . . . 9

Historical Progression of Terms and Present Definitions . . . . . . 9

Historical Changes in Terminology Present Definitions of Apraxia and Dyspraxia 
Localization of the Lesion in Apraxia and Dyspraxia

Etiology

Incidence

Definitions of Related Disorders and Their Differentiations from Apraxia . . . . 28

Characteristics of Apraxia or Dyspraxia and Treatment

Characteristics of Apraxia or Dyspraxia Intervention Prognosis

III METHODS AND PROCEDURES . . . . . . . . 49 Selection of Subjects . . . . . . . 49 Audiometric Screening

Level of Intelligence and Comprehensive Language Functioning Articulation Other Variables

Administration of the Test Battery . . . 54

Examiner .......... 59

Data Analysis . . . . . . . . . 59

IV RESULTS AND DISCUSSION . . . . . . . 60

Results............. 60

Discussion .......... . . 65

$\mathrm{V}$ SUMMARY AND IMPLICATIONS . . . . . . . 81

Summary . . . . . . . . . 81

Implications .......... . 83 Clinical Research

SELECTED BIBLIOGRAPHY • • • . • • • • • • 86 
A DEFINITIONS OF APRAXIA . . . . . . . 92

B CHARACTERISTICS OF APRAXIA . . . . . . 93

C TREATMENT PROCEDURES FOR DEVELOPMENTAL DYSPRAXIA . . . . . . . . . . 95

D DESCRIPTORS USED IN LOCATION OF PRE-DIAGNOSED DYSPRAXICS . . . . . . 100

E MODIFIED APRAXIA BATTERY . . . . . . . 101

F SCORING CRITERIA FOR THE MODIFIED

APRAXIA BATTERY . . . . . . . . . 109 


\section{LIST OF TABLES}

TABLE

PAGE

I Normal/Severe Functional Articulation

Disordered Intergroup Comparisons on

the Modified Apraxia Battery . . . . . .

61

II Normal/Pre-diagnosed Dyspraxic Intergroup

Comparisons on the Modified Apraxia

Battery .. . . . . . . . . 63

III Dyspraxic/Severe Functional Articulation

Disordered Intergroup Comparisons on

the Modified Apraxia Battery . . . . . . 64

IV Significant Items on the Modified Apraxia

Battery .. . . . . . . . . 66

$\mathrm{V}$ Verbal Section Items Approaching Significance

at the .05 Level on the Modified Apraxia

Battery . . . . . . . . . 71

VI Nonverbal Section Items Approaching

Significance at the .05 Level on the

Modified Apraxia Battery . . . . . . 72 


\section{CHAPTER I \\ INTRODUCTION, STATEMENT OF PURPOSE, \\ DEFINITIONS AND LIMITATIONS}

\section{Introduction}

The majority of students attending public schools develop adequate speech without assistance. Others are not so fortunate. There are an estimated two and one half million children and young adults in the United States with a communication disorder (NINDS, 1970). More than 60 percent display a "functional" articulation problem, a disorder which forms the largest share of the caseload of a public school speech pathologist. Valuable time and money are spent in treatment of this category of articulation disorders for which no "clear-cut" cause has been diagnosed. Yoss (1973a) has stated:

The term functional as applied to an articulation disorder connotes the following possible interpretations in the literature:

1. A disorder in the speech production where specification of an organic or structural etiology cannot be determined, and thus the capacity for normal function exists.

2. The disorder is related to a psychological or emotional factor.

3. The inadequate functioning of the articulators remains as a residual despite the fact that the organic deficit which might have been the underlying cause has been corrected.

A child may learn the pattern for speech incorrectly or 
may simply retain infantile patterns in later speech (Johnson, Darley, and Spriestersbach, 1963). These speech problems should be correctable with instruction in production of acceptable speech patterns and with strong reinforcement for continued use.

Improper articulation also may result from organic conditions. An "organic" articulation disorder is caused by some form of pathology which interferes with adequate speech production. Examples are speech problems due to cerebral palsy or cleft palate. According to Johnson et al. (1967), however, ". . In the majority of articulatory cases no significant organic factor can be found."

Treatment methods for "functional" articulation disorders have traditionally begun with some form of auditory discrimination or "ear" training. Treatment then progresses from production of a new speech pattern in isolation, nonsense words and syllables to sentences and conversational speech. Sensory input to the child is primarily via the auditory modality.

Some children with severe articulation disorders progress extremely slowly with traditional methods of articulation intervention with as many as one to five years of treatment. It would seem logical to question, therefore, whether or not these individuals are indeed "functional" articulation cases. Evidence presented by Yoss $(1973 a, b)$ indicates developmental dyspraxia may be the cause of some severe articulation problems in children who do not respond readily to 
treatment.

Apraxia as a disorder separate from aphasia, though often found in conjunction with 1t, has been most thoroughly examined in adults. Although it had been mentioned in the literature as early as 1861 , not until the 1950's did writers emphasize that symptoms resembling dysphasia and dyspraxia were noted in young children who had suffered no obvious post-natal cerebral insult. Morley, in 1954, was the first to classify the set of symptoms as "developmental articulatory dyspraxia" when they occurred in children.

Diagnosis and treatment of developmental dyspraxia is becoming an area of growing interest and concern to the speech pathologist as awareness of the disorder increases. Fay (1974) suggested that, even with the currently available information about dyspraxic children, it continues to be difficult to separate them from dysarthrics, childhood aphasics, and "functional" articulation cases. He further postulated that until these differentiations are made, it will be difficult to plan effective treatment for the dyspraxic child. Further study which might contribute information to aid the speech pathologist in discriminating dyspraxia from other disorders in children seems to be warranted. Perhaps a tentative explanation of etiology might be provided for some proportion of so-called "functional" articulation disorders. As Kools and Tweedie (1973) pointed out, a review of the literature shows " . . a growing need of assessing clinical speech populations for the presence of apraxic disturbances." 
Statement of Purpose

The purpose of the present investigation was to determine if children labeled as "severe" functional articulation disordered, who have been enrolled in public school speech programs for one year or more, exhibit dyspraxic-like characteristics. Specifically, four hypotheses were tested:

1. There will be a statistically significant difference in the scores on the items of the Modified Apraxia Battery between the severe functional articulation disordered subjects and the normal subjects.

2. There will be no statistically significant difference in the scores on the items of the Modified Apraxia Battery between the severe functional articulation disordered subjects and the "pre-diagnosed" dyspraxic subjects.

3. There will be a statistically significant difference on the scores on the items of the Modified Apraxia Battery between the "pre-diagnosed" dyspraxic subjects and the normal subjects.

4. Particular items on the Modified Apraxia Battery will significantly differentiate those displaying dyspraxic-like characteristics from those who do not.

\section{Definitions}

The following are descriptions of terms used operationally in this study.

\section{Apraxia}

For purposes of this investigation, apraxia will be defined as ". . an inability to perform a skilled voluntary act despite absence of paresis or incoordination of muscular control" (Darley, 1964). Historically, apraxia has been 
reserved either for adults who have suffered a brain insult or for a severe disordered condition in both children and adults. Apraxia has been categorized into three types, Iimb apraxia, oral apraxia and verbal apraxia. Iimb apraxia is a problem in motor performances or visual motor skills involving arms, hands, legs or feet; oral apraxia is a problem in voluntary movements with muscles of the larynx, pharynx, tongue, lips and cheeks; and verbal apraxia is a problem in the mechanics of correct verbal formation in which an individual cannot correctly set the speaking processes into motion.

Apraxia Battery

An apraxia battery is a collection of test items designed to locate and delineate the presence of apraxia.

\section{Dyspraxia}

Dyspraxia is a term often used synonymously with apraxia and, therefore, generally identifies the same set of characteristics. Dyspraxia has been reserved either for children who display developmental brain insufficiency or for a less severely disordered condition in both children and adults. Dyspraxia generally denotes "dyspraxia of speech" while apraxia may refer to limb, oral or verbal apraxia. Apraxia and dyspraxia are used synonymously throughout this investigation unless otherwise noted. 
Eupraxia

For purposes of this study, eupraxia is defined as ". . - good or correct manipulation or handling of objects or applying them to a useful purpose. Eupraxia is the condition which exists before apraxia develops" (Nielson, 1936).

\section{Functional Articulation Disorder}

A functional articulation disorder may be defined as " - a disorder in the speech production where specification of an organic or structural etiology cannot be determined, and thus the capacity for normal function exists" (Yoss, 1973a). This type of speech disorder often has no other cause than failure to learn correct speech patterns.

\section{Modified Apraxia Battery}

The apraxia battery utilized in this study was developed by this investigator through combining portions of two other apraxia batteries (Wertz and Rosenbek, Yoss, 1973a). It is composed of verbal and gestural production tasks and is scored and recorded on a test blank. It is comprised of ten tests designed to measure verbal apraxia, one test designed to measure oral apraxia and one test designed to measure limb apraxia. This battery was termed Modified Apraxia Battery to distinguish it from the original Rosenbek and Wertz test collection which was called Apraxia Battery.

Pre-diagnosed Dyspraxic

A pre-diagnosed dyspraxic was defined as a client 
diagnosed as dyspraxic prior to the date of this study by speech pathologists at the Crippled Chilaren's Division, University of Oregon Medical School, Portland, Oregon.

\section{Severe Functional Articulation Disorder}

A severe functional articulation disorder is a speech production disorder with no obvious organic or structural etiology which meets the following criteria: 1) misarticulations are produced, consistently or inconsistently, on four or more separate and distinct phonemes; and 2) progress in correction of errors is extremely slow or difficult.

\section{Iimitations}

Following are two limitations involved in the research procedures of this investigation.

Use of Nonstandardized Instrument

No one as yet has devised a test battery for measurement of dyspraxia in children which has been standardized. This, however, should not prevent researchers from examining an area in which much information is needed and in which correct diagnosis of dyspraxia is of growing concern. In their analysis of fifty-two children with dyspraxia of speech Wertz et al. indicated "In over half the cases, an intensive pediatric neurological evaluation revealed essentially normal results -.." Some form of evaluation, other than the neurological, will provide the public school clinician with indications of apraxic involvement; therefore, a measurement, even 
if nonstandardized, which provides indications of dyspraxiclike characteristics in functional articulation groups could provide a clinician with some valuable information to aid in designing intervention.

Previous Treatment of Pre-diagnosed Dyspraxics

Pre-diagnosed dyspraxics may have recelved speech and/ or language intervention prior to the date of this study. Such treatment was beyond the control of this investigation and results of the study should be viewed with this in mind. 


\section{CHAPTER II}

REVIEW OF THE LITERATURE

The following review of the literature includes: 1) an examination of historical changes in the meaning of the term "apraxia" and of the most recent definition(s) of apraxia, dyspraxia and developmental dyspraxia; 2) a discussion of information on localization of the lesion, possible etiology and incidence of the disorder; 3) definitions of related disorders often confused with or found in conjunction with dyspraxia and a differentiation of dyspraxia from these related disorders; and 4) a description of the characteristics of dyspraxia by which it may be recognized including proposed treatment methodologies for dealing with the disorder.

\section{Historical Progression of Terms and}

\section{Present Definitions}

\section{Historical Changes in Terminology}

The diagnosis of "childhood developmental dyspraxia" is a relatively recent phenomenon in the United States, gaining momentum since about 1965. Recognition of adult apraxia (a closely related disorder) goes back much further in the literature. To fully understand the difference in the two diagnoses one must examine the progression of ever-changing terms which have been applied to this particular set of character- 
istics known as apraxia.

While examining adult aphasic patients who had suffered cerebral insult, Broca, in 1861, described and delineated a disorder which he considered to be an impairment of a specific "faculty for articulated language" separate from the "general faculty of language" (Darley, 1968). Today one would refer to this "articulated language" disorder as a speech articulation disorder. He labeled this collection of characteristics aphemia; the general language disorder was termed verbal amnesia. He hypothesized the articulation disorder appears when an individual experiences a lesion in the posterior portion of the third frontal convolution of the brain. Individuals with aphemia were described as having adequate hearing and comprehension of spoken language, expressing themselves effectively with gestures, showing no paralysis or deviation of the tongue, yet being severely limited in their oral expression.

Authors since Broca have taken considerable liberty in applying to this same set of characteristics other names which they considered to be more appropriate. Darley (1968) has provided a chronological progression of change in terminology in the last 107 years. This progression will be reviewed here to aid in understanding the varying terms encountered in the literature. Trousseau, writing in 1864 , apparently promulgated much of the existing confusion by applying the term "aphasia" to both aphemia and verbal amnesia, claiming there was no valid distinction between the two. 
Though writers continued to describe a disorder with the characteristics of Broca's aphemia (Jackson, 1866, is one example), no one disputed Trousseau's use of one term to denote both disorders for some years. Wernicke, in 1874, described an impairment of language comprehension due to a lesion of the first temporal convolution in the dominant hemisphere of the brain. This he designated as sensory aphasia. He felt it was separate from motor aphasia, 1.e. Broca's aphemia, a disorder in which the patient cannot say words but can understand them. Aphemia came to be known as Broca's aphasia, then motor aphasia, and later subcortical motor aphasia (Darley, 1968).

In 1906, Pierre-Marie expressed a point of view supporting a distinction between difficulty in comprehension of language (true aphasia) and that referred to by Broca as aphemia, the latter of which he called anarthria. By this term, he meant a ".. - loss of control of all those complex mechanical aptitudes which are employed in the exteriorization of language" (Darley, 1968). He was describing what one today would refer to as "programming the movements of oral speech." He stated this disorder can and does exist separately from aphasia though they are also found together. He agreed with Broca that an individual with this disorder can understand, read, write and has normal intellectual capacity. A battle ensued between Pierre-Marie and Dejerine, another author of the period, who claimed the term anarthria indicated the presence of paralysis of the speech musculature. (Current 
authorities have adopted Dejerine's point of view and have reserved the word anarthria to refer to speech problems resulting from a loss of motor power.)

Use of the term "apraxia" has been attributed to many writers (the first probably in the late 1800's), but the first important mention of the word was in the writings of Liepman around 1900. He was the first to comprehensively analyze the characteristics of this disorder as he encountered the symptomology in clinical situations and to classify the disorder as "apraxia." He defined it as

. . inability to .. perform specific skilled acts with certain parts of the body in a purposeful manner, although the power of movement is intact, the patient understands what is required of him but he cannot execute the action he wishes to perform (Darley, 1969).

Liepman provided three main classifications of apraxia to which some later writers have added other categories. The original classifications were: 1) limb-kinetic apraxia, 2) ideo-kinetic apraxia, and 3) ideational apraxia (Head, 1963). The classification of ideo-kinetic apraxia - corresponded to what Liepman had originally cailed 'motor apraxia' and which constituted a deficit in the use of objects even though they were perfectly recognized (limbs, face, and articulatory structures were disturbed in their movements) (Yoss, 1973a).

Apraxia of speech would seem, then, to fall under this category •

The term "motor aphasia" also was consistently used around 1900, although there was much argument over the exact nature of the oral expressive disorders in "motor aphasia." 
One school of thought held that the speech disturbances were due to a loss of motor images or engrams for words. The individuals lost the memory of the movements needed to articulate words; therefore, oral expressive disorders were seen as entirely aphasic in nature. Inner speech also was believed to be impaired.

Another view held that the expressive deficit involved only the motor mechanism of articulation, which corresponds to the present day conception of dysarthria. Liepman (in Head, 1963) and Neilsen (1936) felt neither hypothesis to be correct. Rather, motor aphasia was the same entity as apraxia, specifically an apraxia of the glosso-labio-pharyngeal apparatus.

In 1920, Henschen proposed returning to Broca's original word "aphemia" as descriptive terminology. It more correctly conveyed, he felt, that the individual was experiencing $a "$. . want of power for coordinating letters and syllables" (Darley, 1968). He contended the individual had "forgotten" the movements of speech. Head (1963) also emphasizing the "forgetting" of the movements of the articulators, chose to label it "verbal aphasia." Terminology was further confused when Weisenberg and McBride, in 1935, termed the disorder "predominantly expressive aphasia" (in Darley, 1968).

In 1939, the term "phonetic disintegration" was proposed by Alajananine, Ombredare, and Durana. It has been perpetuated in the $1950^{\prime} \mathrm{s}$ and $1960^{\prime} \mathrm{s}$ by Wepman who felt that the 
idea of "phonetic disintegration" conveyed that the disorder was a transmissive problem (in Darley, 1968).

Reporting in a 1964 book entitled Disorders of Language, Professor Eberhard Bay of Dusseldorf (in Darley, 1968) described a group of aphasics which did not resemble others. Though they would usually be classified as motor aphasics, he labeled them "cortical dysarthrics" emphasizing that their disorder was not genuine aphasia and should be distinguished from it. His point was well taken but one wonders why he did not choose either "aphemia" or "apraxia" as a delineating term rather than further confusing the situation by use of the term "dysarthria" when no paralysis was evident. This choice seems no more precise or descriptive than use of the word aphasia.

Studies conducted more recently (DeRenzi, Pieczuro, and Vignolo, 1966; Shankweiler and Harris, 1966, 1968; LaPointe, 1969; Deal, 1970; Johns, 1970; Rosenbek, 1970; Aten, 1971; Yoss, 1972; Rosenbek and Darley, 1973; Yoss, 1973a, b) reveal characteristic phenomena in this disorder which are best studied and described under the term apraxia, particularly apraxia of speech as clearly differentiated from aphasia, dysarthria, and other disorders with specific language deficits, muscle involvements or paralyses.

The same problematic situation is encountered in examining descriptive terminology relative to "apraxic-like" speech in children which is evident in attempting to make sense of terms which have been applied to an apraxia of 
speech acquired as a result of cerebral insult. These cases of disordered articulation in children have been referred to as
' 'developmental dysarthria', 'central dys- arthria', 'articulatory dyspraxia', 'developmental articulatory dyspraxia', 'executive aphasia', 'a- praxia or dy spraxia of 'speech', 'expressive aphasia', 'motor speech delay', 'motor aphasia', and 'cortical dysarthria' (Yoss, 1972).

other names offered for apraxia seen in individuals of all ages are: apractic aphasia, Broca's aphasia, motor aphasia, verbal aphasia, and aphasia with loss of speech.

It is evident there is yet no particular agreement about how one should consistently refer to this particular set of clinical manifestations. Nevertheless, this author agrees with Johns (1970) in stating,

study of this particular motor-speech dis-
order has been ${ }^{-}$a fertile field for theoreti-
cal and interruptive arguments in which the con-
tenders do not always define their terms ${ }^{-}$. Ac-
ademic posturing about terminology for the sake of
terminology is an arid and futile exercise.

Present Definitions of Apraxia and Dyspraxia

Definitions of apraxia are variously stated but all reflect very nearly the same notion as the definition provided by Liepman stated earlier. One of the most recent was prom posed by Darley, "Apraxia refers to an inability to perform a skilled voluntary act despite absence of paresis or incoordination of muscular control" (Darley, 1964). For other definitions, see Appendix A.

Apraxia has been categorized into three basic groups: 
1) Iimb apraxia, 2) oral apraxia, and 3) verbal apraxia or apraxia of speech. Many of the first instances of apraxia reported in the literature were non-verbal (1.e., limb apraxias) manifested in problems of general motor performance or visual-motor skills. Individuals with non-verbal apraxias have problems with normal, routine movements. Writing may be affected in addition to combing hair, cutting with scissors, playing games, tying shoes and myriads of other activities demanding performance of an ordered sequence of events. Similarly,

'Oral apraxia' may be defined as the inability to perform voluntary (i.e., on command) movements with the muscles of the larynx, pharynx, tongue, Iips and cheeks, although automatic movements of the same muscles are preserved (DeRenzi, Pieczuro, and Vignolo, 1966).

This must be distinguished from verbal apraxia which is the inability to produce, voluntarily, speech sounds, words, et cetera. Blakeley (1972) hàs stated,

Verbal, or speech, dyspraxia is the breakdown of accurate muscle function associated with talking. These same speech articulation muscles may fail to function accurately for non-speech acts as well, but this is not always the case by any means. If this occurs, then oral dyspraxia (apraxia) rather than verbal dyspraxia (apraxia) is the appropriate terminology.

Other writers (Darley, 1964; Wertz et al., 1970) agree it is the programming or sequencing of muscle movements which is impaired and understanding of speech is adequate.

Verbal apraxias are believed by most researchers to be basically independent of the symbolic process. Symbols can be formulated, the syntax of the language is intact, but the 
individual either cannot remember the movements to produce speech or he does not know how to control or set in motion the actual speaking processes. The individual insists that he knows what he wants to say, but when he attempts to speak he produces a series of mispronounced, mutilated words. It seems to be the "mechanics of verbal formation" that are causing the problem, not the power of naming (Head, 1963). For those who are the most severely impaired and have no spoken language, communication is accomplished primarily through gesture and pantomime. Some, however, may not even be able to produce gestures.

"Dyspraxia" is the other term often heard in reference to the same general disorder as "apraxia." The two terms are largely synonymous although historically "apraxia of speech" has been reserved for the disorder seen in adults who have suffered some form of insult to the brain. "Dyspraxia" generally identifies the same set of characteristics as they appear in a child for whom there is no etiology of known brain insult. For some researchers, however, the two terms delineate a difference in the severity of the disorder.

Dyspraxia is a breakdown in speech articulation related to positional and movement sense. One or more of the articulators do not seem to have an entirely appropriate 'memory bank' so that they may fully profit from imitation or experience. In severe cases, this 'memory bank' appears to be bankrupt and ail consonants may be defective, that is, volitional control of the speech articulators may be virtually absent. This severe form is usually called apraxia rather than dyspraxia (Blakeley, 1972).

Since apraxia has been the center of much terminologi- 
cal dispute during the last seventy to eighty years, many descriptions of the disorder have been offered in the literature under other names. In 1974, however, Martin proposed apraxia is not a distinct disorder from aphasia but rather is a part of the total aphasic disorder or a manifestation of it. He summarized:

- . the evident influence of other linguistic variables on phonological production demonstrates that there is not a discrete separation of motor activity from other language processes, or their possible impairment [aphasia] . . The various symptoms [of so-called apraxia] taken separately or together may have alternate interpretations that do not lend themselves to the concept of motor impairment.

He has proposed the term aphasic phonological impairment. Johns and Darley (1970) have formulated the opposite opinion:

because apraxia of speech focuses on the underlying
dynamics of the disorder. Apraxia of speech ex-
plicitly 1) directs one's attention to the motor
aspects of speech, 2) emphasizes the volitional ex-
ecution of articulation, 3) excludes significant
weakness, paralysis and uncoordination of the
speech musculature, and 4 ) indicates a discrep-
ancy between the execution of the speech act and
relative linguistic intactness.

It can be seen that agreement has not yet been obtained about the distinct nature of the disorder. This author contends, nevertheless, the characteristics by which one recognizes the problem have remained relatively stable in form as they have appeared in the literature since the early 1900's. The disorder, as an entity, does exist and speech pathologists must deal with it, regardless of the name by which it 
may be ultimately identified. Those who are struggling with production of speech must be diagnosed according to these characteristics and appropriately placed in some form of remedial program.

Discussions of apraxia often include localization of the disorder in adults. Localization in children, however, is much less well designated. The following section discusses localization of the lesion in dyspraxia, possible etiology of the disorder and incidence.

\section{Localization, Etiology and Incidence}

Localization of the Lesion in Apraxia and Dyspraxia

Researchers for many years have attempted to localize the exact area in the brain where a lesion had occurred resulting in apraxic characteristics. Beginning with Broca in 1861, through Liepman in the early 1900's, until the present day, many have postulated which area of the cerebrum or surrounding tissue has been damaged. This interest in locating a lesion flourished during World Wars I and II as soldiers with injuries to the head made study of the problem a pressing concern. Post-mortem examinations of brains of stroke patients also have provided much information. Most investigators (Neilsen, 1936; Liepman in Head, 1963; Head, 1963) have experienced extreme difficulty in finding a strictly limited lesion in the brain which automatically produces apraxia. Liepman (in Head, 1963) concluded, however, both the left hemisphere and the fibers of the 
corpus callosum are involved. "Ideo-motor apraxia" is more likely to appear, he felt, when the central convolutions are severed from the visual, auditory, and tactile regions of both hemispheres, especially the left. More anterior lesions appear to be associated with "motor apraxia."

Neilsen, writing in 1936, discussed much of the history of localization of apraxia. He spoke about four main areas historically believed to be especially "potent" for developing apraxia. These are: 1) the left parietal lobe, 2) the motor-strip, 3) the parieto-occipital region and 4) the corpus callosum. Liepman (in Neilsen, 1936) discussed these four regions of the brain in relation to his three types of apraxia. He stated, for example, ideo-kinetic [ideo-motor] apraxia, the classification which included verbal dyspraxia, usually results from a large lesion to the left posterior parietal region or to the corpus callosum. In this form, a functional interruption occurs between an intact ideation and intact crude motor function. The patient is, therefore, unable to execute his ideas. Head (1963) emphasized another point of view regarding the issue of localization. He stated:

- although . . rules with regard to the lesions capable of producing apraxia are roughly correct, it must not be forgotten that the destruction of tissue is always severe and the brain usually shows in addition widely diffuse changes. The disorder of function may be distinctive in character and occupy certain definite parts of the body, although the anatomical changes are not confined to a single focus.

The literature strongly indicates the disorder of 
apraxia may very well originate in a disruption of the assoclation fibers connecting several different areas of the brain (Wepman, 1951; Wertz et al., 1970; Blakeley, 1972). According to Wepman (1951), Bastian has indicated aphasic conditions in which individuals experience speaking difficulty without a defect in comprehension are produced by ". . an anatomical defect in the connective neural tissue between the 'cortical gray matter' and the center for muscular control of the movements of speech." Bastian's statement was supported in an investigation by Wertz et al., (1970) using the electroencephalograph, contrast studies and surgical reports to provide 1ocalization information. Results of their examination of patients with acquired apraxia of speech showed that 49 of 108 patients" -. had lesions in the third frontal convolution [Broca's area] and 59 had lesions in other areas." To further investigate the site of lesion and attempt to confirm these results, 21 cases with the most well-documented lesion were isolated and examined. Wertz et al. concluded a variety of lesions in the left hemisphere may result in apraxia of speech and lesions not involving the third frontal convolution also may be associated with this disorder. Hence, the concept of specific localization was not upheld.

These results do not discount the importance of Broca's area in motor speech behavior, but they suggest apraxia may result from lesions in the third frontal convolution or lesions in cortical tracts connecting the third frontal convolution with other areas which are important to speech and 
language behavior. This point of view would, perhaps, explain a phenomenon which has puzzled many researchers, 1.e., different locations of brain lesions producing such similar disruptions in behavior.

Wertz et al. (1970) suggested localization of a dyspraxic involvement in children is even more difficult than in adults. As childhood developmental dyspraxia has been delineated and diagnosed relatively recently, and as these children are most often normal in many other respects, there has been Iittle opportunity for post-mortem examination to determine possible malfunctioning brain tissues. Neurological examinations seemingly do not effectively locate the source of the problem. Ultimately, observation of behavioral characteristics would be more helpful in planning intervention than would attempts at localization of the disorder.

\section{Etiology}

Closely related to the topic of localization in the disorder of apraxia is etiology. Many writers (Brain in Morley, 1959; Gordon, 1964; Gatz, 1970) have separately formulated the same general conclusion: apraxia is caused by a defect in cerebral function at the highest level. Much of the explanation for the disorder, they feel, may be found in the interruption of trans-cortical fibers, Edwards (1973) stated, "It is probably more accurate to regard this impairment as being associated with neurophysiological dysfunction rather than with anomalies of neuroanatomical structure." In this regard, 
one is reminded of a cord which has simply become unplugged from an electrical outlet, rendering the attached appliance motionless though not incapable of correct operation. With the less severe condition of dyspraxia, one could well imagine a "short" in the "wiring" which produces incorrect but partial operation of the involved mechanism.

To produce a voluntary act, such as speech, . there must first be an idea, a mental formulation of the plan. This formula must then be transferred by association fibers to the motor system where it can be executed . . . Iesions . . . apparently cause apraxia by cutting off impulses in association tracts. The idea is formed correctly but mistakes occur in translating it into performance (Gatz, 1970).

Rosenbek et al. (1973) have postulated the problem may be caused or aggravated by some form of oral-sensory perceptual deficit, a ". . difficulty in processing orally received sensory information." The problem would seem to lie, then, somewhere between the brain itself and the end organ. At any rate, there is a problem in reception at the level of the end organ. They do conclude, however, that not all apraxia is due to an oral-sensory deficit. Rather certain kinds of phonemic errors, such as distortions, may increase as a result of this type of deficit.

A recent author has discussed the nature of the particular "association tracts" which might be involved in the lesion producing the disorder. Norley (1959) postulated a breakdown either between the receptor and effector processes or in the association areas when language comprehension is apparently 
normal. The problem may be poor auditory memory for speech sounds; also the individual may fail to develop or may lose access to normal patterns of articulation. The "cortical motor mechanism" is intact but cannot adequately be activated or controlled by the receptive processes. Morley, writing later with Fox (1969) reemphasized this general conception of the problem. The terms sensory and motor processes, however, were substituted for the receptor and effector processes above. The disorder was described as a problem resulting from a disturbance in the sensorimotor pathways for speech in the nervous system. Whether the mechanism affected is mainly motor or sensory or the pathways between the two is not clearly established. Rosenbek et al. (1974) have suggested it is both a motor and sensory disorder. Fay (1966), in discussing metathesis (a phenomenon involving consonant transposition with reversal of order, often found in apraxia of speech) has stated correct perception and production of speech relies upon both auditory [sensory] processing of the acoustical signal and motor adjustment. He continued by saying the ".. . two processes operate as a binary system to 'integrate, mesh and interlock, the elements of speech - . ." Johnson and Myklebust (1967) also postulated a problem in auditory-motor integration proposing that the rudiments of the problem emerge during the stage in which the child is babbling. They theorize the child never discovers he can produce a specific sound by moving his tongue, lips, and teeth, et cetera, in a certain way. Case histories 
frequently indicate dyspraxics are silent babies who do not babble and when they do, they use mostly vowels with varying inflections.

If the problem really lies in integrating the sensory and motor systems, might there be a way of describing this integration problem? For the words to be integrated with the motor system, they must be held in mind. Apraxia, therefore, may be due to an inability to remember the motor patterns needed for speaking (Agranowitz and McKeown, 1964; Johnson and Myklebust, 1967). Although the ability to recall the words remains intact, the patient has lost the memory of the movements for producing words. Aten et al. (1971) have proposed an apraxic speech disturbance may be due to a breakdown in kinesthetic and proprioceptive sensory receptors rather than auditory receptors. He also suggested looking to an auditory memory deficit as a possible factor. Fay (1966) has postulated an auditory memory problem as a partial explanation of metathesis.

Fawcus (1971) and Edwards (1973) separately have proposed yet another interesting hypothesis. Edwards has noted some researchers have observed dyspraxics appear unable to select meaningful input signals and to reject redundancies in the surrounding environment. Fawcus additionally has proposed the central nervous system of dyspraxics may be experiencing difficulty dealing with conflicting input data patterns, those of the auditory, kinesthetic, acoustic and tactile feedback resulting simultaneously from action of the 
speech musculature and his own auditory memory derived from the phono-articulatory action. His "... problems may be due to 'noise' in the link between the metalinguistic decision system or encoding stage and the effector selector."

Although the exact etiology is a matter of some disagreement, the results of the disorder seem to be $a$ ". . . disorganization of the process by which phonological units are encoded for production" (Shankweiler and Harris, 1966). There is a disturbance of the coordinated sequencing of one or several articulators. Fay (1966) referred to this disruption as ". . inability to perceive temporal order."

Whatever the cause of apraxia in adults, an explanation or discussion of it must include a feasible way to account for the occurrence of the same or similar symptoms described in children. Wertz et al. (1970) have reported, in their examination of twenty-eight cases of pure apraxia of speech in children, an undetermined etiology contributed to 75 percent of the cases.

One consideration remains to be discussed with regard to etiology in children with dyspraxia. What external causes result in the underlying condition, the minimal cerebral insult or lack of development? Possible causal factors include seizure disorder, diffuse central nervous system disease, genetic influences, maternal infection, maternal dietary imbalance, maternal hormone activity, toxicity perhaps due to medication even including aspirin (Morley and Fox, 1969; Wertz, 1970). The above have been cited in the past as pos- 
sible causes of such anatomical defects as cleft palate which may be caused by some sort of interference with normal development during the formative embryological period in the first trimester of pregnancy. Such conditions might some day be shown responsible for interference with development of the nervous system later on in fetal growth resulting in disorders such as developmental dyspraxia (Morley and Fos, 1969).

\section{Incidence}

Iittle information is available in the existing literature describing the incidence of dyspraxia of speech, especially in children. The exact incidence is unknown, partially because verbal dyspraxia has been widely recognized and diagnosed in this country as a distinct entity only since roughly 1968 (Ferry, 1974). Incidence of the disorder is further complicated by the fact that dyspraxia can occur in isolation or in combination with other disorders such as dysarthria, aphasia, or both. Wertz et al. (1970) have reported that in a study of 52 children, 54 percent displayed apraxia of speech, 33 percent were apraxic and dysarthric, 11 percent were apraxic and aphasic, and 2 percent displayed apraxia, aphasia and dysarthria in combination. No estimated percentage of occurrence in the total population has been reported; however, Wertz et al. in the conclusion to their study have stated, "Apraxia of speech occurs more frequently than is indicated by the number of cases reported in the 
literature." Ferry (19.74) also has estimated that the true incidence is ".. probably at least $10 \%$ of articulation problems in school age; higher than recognized."

\section{Definitions of Related Disorders and Their}

\section{Differentiations from Apraxia}

One of the difficulties with any study of apraxia or dyspraxia is that the disorder may or may not be found in combination with other closely related disorders which mistakenly may be assumed to be a part of the apraxia itself. To aid in understanding apraxia, it should be clearly differentiated from other conditions affecting learning and behavior.

Again, apraxia, or dyspraxia, of speech is defined as difficulty in voluntary control of the musculature of speech in the absence of paresis or uncoordination.

Two disorders which often are found in association with dyspraxia and, therefore, should carefully be separated from it are "dysarthria" and "aphasia or dysphasia." Johnson and Myklebust (1967) described dysarthria as a paralytic involvement affecting expressive language, speech production, and articulation, deriving from disorders of the central or peripheral nervous system and resulting in faulty innervation of speech musculatures in complex acts.

With regard to the actual formation of the sounds of speech, one could say the following of the dysarthric: he knows how to make all sounds, he knows where to place his 
tongue and lips, but because the articulators are paralyzed and restricted in movement, they cannot be placed where he wants. The apraxic has a different difficulty. He indeed knows what it is he wants to say, but unlike the dysarthric, he has no idea where he should place his tongue and lips to produce the sounds. The articulators would move correctly if he knew what movements to make. The apraxic acts as if his "tongue were lost in his mouth" (Johnson and Myklebust, 1967).

Darley (1970) has summarized the distinction between these two disorders:

1. In dysarthria there is evidence of slowness, weakness, or incoordination of the speech musculature. In apraxia, errors produced cannot be referred to any specific muscle group.

2. In dysarthria, all basic motor processes-respiration, phonation, resonance, articulation, prosody-are vulnerable. In apraxia, the breakdown is specifically articulatory with prosodic alterations following as secondary compensating phenomena. Phonation and resonance are not affected.

3. Most dysarthric articulation errors are fairly predictable; usually they are simplifications of a too-difficult task. In apraxia, errors are unpredictable and are typically not simplifications. They may even be complications with errors being unrelated substitutions.

The most discriminating feature of dysarthria, then, is that errors are consistent and predictable which is distinct from dyspraxia wherein error inconsistency and unpredictability are characteristic.

A second associated disorder is aphasia or dysphasia. According to McGinnis (1963), historically two broad categories of aphasia have appeared in the literature: 1) the 
motor or expressive type which in early studies was referred to as aphemia, and 2) the sensory or receptive type which was called word deafness. Today, the term "aphasia" or "dysphasia" refers to language disorders associated with or resulting from brain injury or disease. The most important word in the preceding statement is language. Aphasia is any language problem due to an organic disturbance in cortical tissue in which the defect does not result from faulty innervation of the speech musculature, dysfunction of the peripheral sense organs, or general mental deficiency. The language problem appears in the areas of symbolization, comprehension, and reproduction of concepts (Wepman, 1951). Apraxia is not considered to be aphasia because:

1. The patient's problem when he cannot say 'tornado' is not with processing of the meaning-bearing units of language but with the non-meaningful units, the programming of the elements of speech movements. 2. Pattern of performance in various modalities reveals speaking to be significantly poorer than listening, reading, or writing. Usually there is a marked discrepancy between speaking performance and performance in other language modalities. The problem is 'impairment of the faculty of articulated language' and not impairment of the general faculty of language.

3. Usualiy therapy for aphasia does not help this articulation problem. It is a transmissive problem involving a particular modality (Darley, 1970).

Apraxia may exist with or without a symbolic disturbance, but it is not to be considered the same as that disturbance. Apraxia also must be differentiated from agnosia. An agnostic individual ".. receives information through the senses (auditory, visual, tactile), but is not able to comprehend it. He cannot interpret what he hears, sees, or 
touches" (Johnson and Myklebust, 1967). Darley (1964) stated it somewhat differently when he described agnosia as a "... difficulty understanding a new series of stimuli as they are presented even though he (the person) can recall images previously received along the same modality." This disorder, then, appears not to be a transmissive problem as is apraxia, but rather a disorder in sensory processing in terms of meaning.

Cluttering must be discussed here in relation to dyspraxia or apraxia because of similarities in the two conditions, the most obvious being a problem with the temporal sequencing of speech. Characteristics of cluttering which emphasize its similarity to apraxia are: a) inversions of sounds, syllables, word and sentence particles reflected in deficient auditory feedback; and b) disorientation with elements of time and space (rhythm, rate, syntactic order). The differences between apraxia and cluttering become more evident, however, with further observation. "... The major features of cluttering are first, the excessive speed of speaking; second, the disorganized sentence structure; and third, the slurred or omitted syllables and sounds" (Van Riper, 1963). Characteristically, the clutterer can speak perfectly when he speaks slowly. He rarely, however, can speak slowly for long periods. The true clutterer is not aware of his excessive rate of speech or garbled articulation. He speaks in spurts or torrents of words, which are often interrupted in flow. His speech is difficult to understand; peo- 
ple often ask him to ropeat.

One important distinotion between apraxia and cluttering is that the individual with the latter disorder, even if severe, can speak perfectly if he decreases his speaking rate. A severe apraxic may not be able to volitionally produce speech correctly even with a slowed rate. Additionally, many apraxics are aware of their errors; whereas, according to Van Riper (1963), a true clutterer is not. Finally, definitions of cluttering imply that confused, slurred and distorted speech is due to a disability in language formulation, not in the formulation of motor speech.

The similarities between cluttering and apraxia would seem to suggest the interesting possibility that similar characteristic behaviors are produced by similar etiological factors. Future research may provide clarification of the discussion. The majority of authorities today, nonetheless, continue to view cluttering and apraxia as separate entities. Ataxia also needs to be differentiated from apraxia principally because the two terms are confused due to the similarity of spelling. Ataxia is a disorder in which relevant muscles are correctly innervated, but motor activity is not coordinated normally. The resultant incoordination produces impulsive jerky movements, tremors and disrupted balance. According to Johnson and Myklebust (1967), ataxia is caused by deficits in the central nervous system without paralysis. Speech, writing, gait and general use of the hands may be affected; however, it is a disorder separate from 
apraxia.

Apraxia, at some points in the literature, has been referred to as phonetic disintegration (i.e., a disorder in which speech errors would be considered simplifications in difficulty of production). Johns and Darley (1970), however, stated the types of errors produced in apraxia, particularly substitutions of consonant clusters for single consonants or three-element clusters for two-element clusters, show that this disorder is not one of phonetic disintegration per se. Error productions at times require more effort than would correct speech productions.

The term dysgraphia also may be confused with dyspraxia and requires clarification at this point. According to Johnson and Myklebust (1967), "Dysgraphia is a type of apraxia affecting the visual-motor system." They further described the dysgraphic individual as follows: he cannot transduce visual information to the motor system, he is unable to write or copy words or numbers. It is the fact that he cannot copy which differentiates that disorder from others. Copying is a problem because just looking at the symbol provides no clues to the movement pattern for its production. Additionally, because he cannot transduce visual information to the motor system or imitate what he sees, he may be unable to tie his shoes, open a bottle, or follow a sequence of movements in a game. Dyspraxia, then, is the speech-related disorder similar in nature and etiology to the written disorder called dysgraphia. 
Finally, a word must be said with regard to functional articulation disorders. This problem previously has been defined as ". . a disorder in the speech production where specification of an organic or structural etiology cannot be determined, and thus the capacity for normal function exists" (Yoss, 1973). Johnson et al. (1967) have stated:

most articulatory deviations seem to be
traceable to no other cause than failure to learn
the correct patterns for normal speech.
most important single cause of disorders of arti-
culation is the lack of sufficiently favorable
conditions for the learning of good speech.

The child may have a faulty speech model in the environment. Sometimes there is a lack of stimulation and motivation for good speech; the environment may allow the child to have all his needs met without using adequate speech.

Clearly, apraxia is not a functional articulation disorder, but rather arises from an organic condition, a malfunction at some level in the cerebrum. Therefore, one should not provide the same treatment procedures for it as he would for a functional articulation disorder. This author is of the opinion that some children displaying dyspraxic characteristics at present, are treated as functional articulation disorders in public school caseloads. To ensure correct diagnosis of dyspraxia, clinicians need to familiarize themselves with this condition. The following section describes characteristics most often mentioned in the literature by which it may be recognized. Several approaches to treatment of dyspraxia also are presented. 
Characteristics of Apraxia or Dyspraxia

and Treatment

Characteristics of Apraxia or Dyspraxia

More accurate identification of apraxia is becoming possible since recent studies have added information to the rapidly expanding body of existing literature on the subject. The identification of apraxia of speech is extremely important both for the neurologist and for the speech pathologist. It is important for the neurologist in diagnosis and referral and for the speech pathologist in selection and application of appropriate and specific remedial procedures.

Chappel (1973) has suggested a program for identification of verbal apraxia. This program might be condensed as follows :

1. The speech clinician should make thorough differentiation of dyspraxia from dysarthric involvement.

2. The speech clinician should identify any sensori-motor deficit(s) that subsumes and is vital to speech production and feedback evaluation.

3. The speech clinician should evaluate other sensori-motor processes besides auditory such as the integrity of the tactile mechanism.

4. The clinician should determine volitional control over the articulators. He should study tongue speed and precision of movement in managing a variety of foods.

5. The clinician should assess the adequacy of volitional control of the jaw, lips, tongue.

6. The clinician should inventory phoneme, syllable and word repetories and sound producing gestures habitual in communication and play.

7. The clinician should explore the ability to imitate isolated phonemes and monosyllabic and polysyllabic utterances.

8. A distinctive feature analysis may help in delineating areas which need work. 
The characteristics which one might expect to find with the above testing procedures are varied. Studies reported in the literature have provided descriptive diagnostic procedures which are generally similar to one another and delineate some similar characteristics. Several of these characteristics of apraxia have been compiled and presented here together with references citing them in research results.

The speech of an adult apraxic is characterized by prominent phonemic errors such as additions, omissions, substitutions, distortions and repetitions. Errors tend to be offtarget approximations of desired productions; however, both errors and correct phoneme productions tend to be inconsistent. The individual often is aware he is producing sounds incorrectly but cannat correct them. He thus anticipates errors resulting, often, in prosodic disturbances, slowed rate, even stress and even spacing. Phonation and resonation are usually unaffected. The apraxic seems, in essence, to be "tiptoeing" through speech. An outside speech model is usually not immediately helpful as imitative ability is poor. Groping for correct positioning of the articulators is common. It increases, as do other forms of articulatory difficulty, as the word length increases. (Head, 1963; Darley, 1964; Shankweiler and Harris, 1966; Johnson and Nyklebust, 1967; Darley, 1968; Johns, 1968; LaPointe, 1969; Deal, 1970; Johns, 1970; Johns and Darley, 1970; Edwards, 1973; Rosenbek et al., 1973). Other characteristics which have been mentioned in the literature appear in Appendix B. 
An analogy may be drawn suggesting that dyspraxia be compared to an inability to control pitch in singing a song. The individual oannot assume control of pitch yet he can recognize a tune and even may be aware of his errors in pitch. In dyspraxia the lack of control of the speech process can be very frustrating and may cause emotional problems which tend to compound the disorder. One can understand the reason for such frustration when the problems in producing speech are illustrated.

The typical apraxic subject .. . might insert the schwa once (thereby sounding somewhat like a dysarthric subject), unequivocally say /spl/ correctly the second time, repeat and block it on the third presentation (a stuttering-like response), make a totally unrelated substitution the fourth time, emit a particularly difficult sequence of phonemes (sukpltweeing for spleen) the fifth time, make a substitutive simplification the next time (speen for spleen), and then say it with the precision of a normal speaker (Johns and Darley, 1970).

Johns and Darley (1970) quoted the following examples of typical statements made by adult apraxics about their problem:

I have it programmed in my head, but sometimes it just doesn't seem to come out of my mouth right.. - I know what I want to say, and its $0 . K$. and other times it sounds wrong; I stutter, but I can write it . . I can't get it going; I can visualize the word and $I$ can say it when I just talk, like in a conversation, but if you ask me to say it, I have trouble.... It's not my language... it's my speech, my speech! I have trouble with my speech!

One cannot proceed to a consideration of treatment methodologies without first raising an important point. We must ask: are characteristics of dyspraxia in children the same as those for adults with apraxia? Yoss, in her 1973a study, 
addressed herself to this topic. She stated:

The clinical reports which implicate an 'apraxiclike' quality in the speech of children have employed descriptive terminology as confusing and misleading as the myriad terms which have historically designated an apraxia of speech acquired as a result of cerebral insult. What articulatory behaviors are we describing when we employ this terminology? If we ascribe an 'oral-verbal apraxia' (or dyspraxia) to a child in the process of acquiring speech and language, one whose neurological maturation is incomplete, is it identical to behavior evident in some brain-injured adults or is it different?

Examination of the literature reveals many of the same characteristics to describe dyspraxia (the term often used in referring to chilören) as were seen in descriptions of apraxia. Contributors to the following description include Ingram (1964), Johnson and Myklebust (1967), Morley and Fox (1969), Fawcus (1971), Blakeley (1972), Yoss (1972, 1973b, 1974), Chappell (1973), Edwards (1973), Rosenbek (1974), Rosenbek et al. (1974) and Yoss and Darley (1974). Articulation is said to be inconsistent. There reportediy may be a reduction in the number of phonemes used. In the less severe cases, articulatory inaccuracies occur mainly during conversational speech, production of polysyllabic or motorically complex words. In more severe cases, all speech shows misarticulations, difficulty in combining and sequencing phonemes, and struggle to deliver speech. Stretches of spontaneous speech may be unintelligible. These children often produce consonants correctly in isolation but have difficulty in making the necessary movement sequences for adding vowels to consonants. 
Ability to imitate speech is less than normal. Two and three feature errors, prolongations and repetitions of sounds, distortions and additions are present when these individuals are asked to repeat a sentence. Repetitions of words with more than one syllable are often produced with the syllables in the wrong order.

The dyspraxic experiences increasing difficulty in production as the length of a word increases. Diphthongs, which require subtle and complex movement sequences, are especially difficult to produce. Even with intense stimulation from a speech clinician, production of words or phonemes is difficult. Progress in therapy is slow.

These individuals produce below average scores on measures of oral diadochokinesis. They require more demonstration than the average child to perform sequences of volitional oral movements (i.e., a kiss followed by blowing, followed by puffing out of cheeks). All speech reveals decreased accuracy and amplitude in volitional oral movements of the lips and tongue. Off-target trial and error attempts at speech production are frequent.

Initiation of utterences is frequently difficult. Prosodic features of speech are often altered, rate is slowed and stress is equalized. Sentences may be shorter than average in length. Articles, prepositions and correct verb forms are often omitted.

In many important areas besides speech, some interesting characteristics also may be evident. Cognitive and 
receptive language performances are essentially normal. Auditory discrimination, though below normals of the same age, is commensurate with other articulation disordered children. Many dyspraxics have normal or above normal intelligence and most evidence normal hearing bilaterally. "Clumsiness", difficulty in fine motor tasks and abnormal gait may be evident. One may be fairly certain in assuming then, many of the same characteristics are found in both adult apraxia and childhood dyspraxia.

Johnson and Myklebust (1967) feel although similarities are evident diagnostically, the congenitally dyspraxic child never acquired the motor patterns for the spoken word and, therefore, differs from an adult. Experience with treatment of dyspraxic children has lead Morley (1959) to conclude that the dyspraxic child differs from the adult in that he is often unaware of his errors in articulation. Not until he finds that his speech does not communicate what he wants, does he note that it is defective. The results of Yoss's $1973 a$ study confirmed that some differences may be apparent between the adult and the child dyspraxic. An accompanying oral apraxia, errors on multiple features of phoneme production and distortions of speech production patterns are characteristic of developmental dyspraxics, though not of adults. Children do not appear to be aware of their errors in articulation (as are adults) until they have participated in some form of intervention. Audible groping and "trial-anderror" placement of the articulators (characteristic of 
adults) are usually not evident unless children are older.

Developmental dyspraxia exhibits characteristics which relate behaviors of this disorder to other forms of neurological impairments. Aten and Davis (1968) concluded about a group of neurologically impaired children,

\begin{abstract}
- . the children with minimal or mild cerebral dysfunction performed more poorly as evidenced in shorter perceptual spans, reduced number of stimuli retained, and less accurate reproduction of sequential information . . They . . were deficient in sequential ordering of multisyllabic words and serial nouns . . These results strongly support theories which state that the perception, storage and reproduction of sequential stimuli is disturbed by cerebral dysfunction. . . Deficiencies associated with certain types of so-called 'functional' articulation disorders may be identified through [testing which reveals these characteristics].
\end{abstract}

Most young children when mastering the production of speech exhibit reversals, insertions, and omissions of sounds. Examples might be "mosacin" for "moccasin", "swikers" for "whiskers", and "aminal" for "animal". The examples of syllable misplacement or sound transposition for syllabic and motorically complex words among preschool and early schoolage children are usually thought of as cute and seldom alarm anyone. One becomes concerned, however, when an eight to twelve year old child exhibits speaking difficulty with most polysyllabic words and cannot correctly order the sounds in some words and diphthongs. A basic abnormality or developmental delay in verbal sequencing ability persists in children, and even extends into adulthood, it becomes of diagnostic and therapeutic concern (Fay, 1966). The difficulty seems to be one of ". . repicturing or reconstructing a 
given presentation in its proper order" (Blakeley, 1972).

Descriptions of dyspraxia lead one to conclude that, being an organically-based articulation disorder, it must not be treated as a functional articulation disorder. Treatment procedures must be specifically and carefully chosen and implemented. The following section is a summary of some of the treatment methodologies for dyspraxia of speech which have been published in the literature together with general comments about organizing and implementing intervention.

\section{Intervention}

A major consideration in the treatment of the dyspraxic child in the public schools is the question of schedules. Public school clinicians, faced with large caseloads and waiting lists under traditional schedules, find themselves limited to seeing most chilären two times a week. ". Those who use a block system may obtain a certain degree of increased flexibility and find time to see some children more than twice a week. This would prove very beneficial for the dyspraxic child. Johns (1970) has stated," . . daily intervention, [and] drill sessions appear to benefit them a great deal more than a once, twice or three times a week approach - . " Problems in intervention with dyspraxia also are evident with a block approach. The dyspraxic child must be seen throughout the school year and preferably all year round. Even with intensive intervention, progress is very slow; much repetition is required to produce improvement. Since 
so much time must be spent in management to accomplish a change in speech, methods of stimulus presentation or reinforcement which are novel may serve to motivate the client and ward of potential boredom. A "reinforcement box" (a mechanical device which immediately dispenses some form of token reinforcement upon correct production of the desired response) for instance, has been shown to be very effective in maintaining high levels of concentrated drill in apraxia intervention. Feedback is immediate. Management, then, must be precisely planned with consideration for the characteristics of the dyspraxic.

Where should one begin? Johns (1970) stated intervention should not commence with the ear training so common to the treatment of most articulation disorders. He said of dyspraxics in clinics,

for the purpose of training their ears. (They re-
port and demonstrate that they know the acoustic
properties of the word they have difficulty produc-
ing.) Instead, direct stimulation regarding the
proper positioning and sequencing of movements of
their articulation appears indicated. An interest-
ing analogy of the large population of children
with so-called 'functional articulation problems
and those who may have an apraxia of speech may be
drawn. For example, the fourth grader enduring his
eighty-sixth ear-training session who can readily
identify a given word out of an infinite number of
acoustically similar words, but who cannot correct-
ly produce that word may be handicapped by an a-
praxia of speech.

There is some disagreement in the existing literature about the point of departure in articulation management with dyspraxics. Johns (1970) feels the initial position of the 
word may be the place to start. Rosenbek et al. (1974) have indicated production of individual phonemes is basically intact; therefore, drill should progress from the syllable unit into words, phrases, and sentences. Wepman (1951) believes an apraxic individual can learn most readily the sound patterns for the most highly visible consonants, i.e., labial, labio-dental or lingua-dental sounds. Next to be taught should be anterior-lingua-palatal sounds, examples of which are $/ s, z, S, 1$, and $r /$. Next taught would be the palatals, $/ \mathrm{k}$ and $\mathrm{g} /$, then $/ \mathrm{ts}, j, z$, and $\eta /$.

Significantly more success can be produced in the clinical situation if the clinician's rate of presenting the discriminative stimulus is considerably slowed which results in greatly increased imitative articulatory proficiency (Daly et al., 1972).

Several treatment procedures have been proposed in the literature. No attempt has been made, however, to group these procedures so that the similarities in all of them may be recognized. Appendix C contains a detailed presentation of some of these specific procedures for treatment of dyspraxia which are different from the traditional approach to articulation intervention.

The focus of dyspraxic management differs from that in traditional articulation intervention. Chappell (1973) has stated " . . effective therapy must establish audiomotor integration (i.e., the association of acoustic events with motor events) and a memory for articulatory behavior" by 
practicing that articulatory behavior repeatedly. Edwards (1973) suggested the basis for a management program for the dyspraxic should be " . . proprioceptive neuromuscular facilitation," in other words, the development of an internal, kinesthetic feedback system to aid in positioning and sequencing of movements of the articulators. Our goal according to Rosenbek (1974) should be to " . . help the child acquire as near normal volitional speech as the physiological limitation will allow" rather than to acquire perfect articulation. Following is a list of intervention procedures used with dyspraxic children which has been condensed from the literature. These procedures illustrate methods which, as a whole, do not form part of traditional articulation management.

1. Make use of equal and even stress and pauses within polysyllabic words, slow overall speech by vowel prolongation, use intrusive schwa (e.g., palent) to aid in production of speech sound clusters (Rosenbek, 1974).

2. Emphasize movement sequences in consonant-vowel and vowel-consonant syllables rather than the sound in isolation (Rosenbek, 1974; Yoss, 1974). 3. Control the distance between successive points of articulation (Rosenbek, 1974).

4. Concentrate on one consonant and vowel at a time (Rosenbek, 1974).

5. Use intensive, systematic drill, much more than in functional articulation intervention; use this type of drill every day (Blakeley, 1972; Rosenbek, 1974).

6. Make use of the visual and all other helpful modalities to aid the auditory modality (Wepman, 1951; Johnson and Myklebust, 1967; Blakeley, 1972; Chappell, 1973; Rosenbek, 1974; Yoss, 1974).

7. Make use of rhythms, intonation, stress, and motor movements to facilitate adequacy of the response (Johns, 1970; Edwards, 1973; Rosenbek, 1974; Yoss, 1974).

8. Begin work with the most visible sounds 
(Johnson and Myklebust, 1967 ; Yoss, 1974 ).

9. Slow the child's rate of speech (Johnson and Mykiebust, 1967; Morley and Fox, 1969).

10. Work to acquire functional useful words as soon as possible (Wepman, 1951; Johnson and Myklebust, 1967; Blakeley, 1972; Chappell, 1973; Rosenbek, 1974).

11. Use practice materials to build child's ability to imitate (Blakeley, 1972).

\section{Prognosis}

Morley has written extensively about the expected prognosis of this disorder. She and Fox, writing in 1969, concluded a severe dyspraxia will not be corrected by the normal process of maturation although it could be modified and improved with appropriate individual training. The course of the disorder depends upon the degree of severity. In the less severe cases, there may be some spontaneous improvement between the ages of four and six years. Visual and other forms of sensory input offered to the child when he learns to read also may allow acquisition of normal or more normal articulation. Where the condition is severe, however, neither spontaneous improvement not reading may make much difference. If articulation is severely defective (sometimes to the extent of rendering the individual unintelligible) and goes untreated, the disorder may persist into adulthood.

How helpful intervention will be for any particular individual is difficult to determine. Ferry (1974) has stated speech intervention procedures may not prove to be any more effective in producing improved speech than maturation. Yoss (1973a) has warned, 
From interpretation of the data, the breakdown in articulation persists . . even after therapy intervention . . at the level of transition from single monosyliabic words of increasing length and phoneme complexity, whether in imitative tasks or in spontaneous speech. It remains to be seen if remedial techniques which utilize strong visual or auditory-visual approaches, with early introduction of sequential material, might substantially reduce the lengthy course of therapy in cases of developmental apraxia of speech.

Intelligible speech and normal articulation may be acquired gradually over a period of several years. Fawcus (1971) also noted that resolving the articulatory deviations takes "considerably longer" than other types of articulation disorders. The preceding review of the literature has revealed the following basic points. First, though several terms historically have been used in referring to the speech disorder examined in this investigation, the terms most accepted today are apraxia or dyspraxia of speech and verbal apraxia or dyspraxia. Apraxia and dyspraxia are generally used synonymously, although dyspraxia recently has come to denote a developmental disorder in children. Secondly, results of localization studies suggest no clear-cut delineation of any one damaged brain area which predictably results in apraxia of speech. There is general agreement, however, that apraxia of speech may result from lesions in the third frontal convolution or in cortical tracts connecting the third frontal convolution with other speech and language areas in the brain. Data relative to children provide no clear conclusions regarding possible location of the insufficiency resulting in developmental dyspraxia. Possible etiologies for the brain 
dysfunction may be an oral sensory-perceptual deficit, a breakdown between receptor and effector processes, a problem in auditory motor integration or difficulty in selecting meaningful imput and rejecting unnecessary information from the environment. There is no agreement as to an exact etiology, but the result is a disturbance in the coordination of the articulators. The exact incidence of developmental dyspraxia is unknown though Ferry (1974) estimated it may compose ". . at least $10 \%$ of articulation problems in schools. . . " Lastly, dyspraxia is a separate entity from dysarthria, aphasia, agnosia, cluttering, ataxia, dysgraphia and functional articulation disorders. It may be recognized by characteristics which differentiate it from these other disorders. Speech clinicians need to familiarize themselves with these characteristics, enabling them to correctly diagnose dyspraxic-like symptoms in their articulation cases. 


\title{
CHAPTER III
}

\author{
METHODS AND PROCEDURES
}

\section{Selection of Subjects}

Twenty subjects were placed in three different groups for purposes of this investigation. The experimental sample was composed of eight individuals meeting the criteria for selection of severe functional articulation disordered subjects. The second group, normal control, was composed of eight "normal" individuals with no speech disorders while the third group, dyspraxic control, was composed of four prediagnosed dyspraxics obtained from the University of Oregon Medical School, Portland, Oregon. The experimental and normal control subjects were selected from a population of students in the following school districts: 1) Gresham Public Schools; 2) Lynch Public Schools; 3) Portland Public Schools; and 4) Rockwood Public Schools.

Eight subjects were selected for the experimental group who met the following criteria:

1. Chronological age from eight to eleven years.

2. Hearing within normal limits.

3. Intelligence quotient of 85 or above.

4. No physical disorder which was the primary etiology of an articulation disorder, such as cerebral palsy or cleft palate.

5. "Severe" functional articulation problem.

6. Enrolled for one year or more in a speech intervention program as a functional articulation dis. order. 
Eight subjects were chosen for the normal control group from those screened in the public schools. Individuals in this population met the above criteria with the exceptions that they had no speech, language or stuttering problems and had never been enrolled in a speech intervention program nor recommended for one.

Four subjects for the dyspraxic control group were chosen from a pre-diagnosed dyspraxic sample at the Crippled Children's Division, University of Oregon Medical School. Subjects in this group met the above criteria except they had already been diagnosed as dyspraxic. They were assumed to have an organic articulation problem; criteria six, therefore, would not necessarily apply to this group. These individuals may or may not have received speech intervention as dyspraxics.

Subjects in the normal and dyspraxic control groups were matched as closely as possible by chronological age to members of the experimental group.

\section{Audiometric Screening}

All subjects received a pure tone audiometric sweep screening at frequencies of $500,1,000,2,000$ and 4,000 $\mathrm{Hz}$ at $25 \mathrm{~dB}$ HL (re: 1969 ANSI). Subjects who failed to respond to any two of the three lowest frequencies $(500,1,000,2,000$ $\mathrm{Hz}$ ) in either ear or $4,000 \mathrm{~Hz}$ in both ears were eliminated from the study (after Yoss, 1973a). 
Level of Intelligence and Comprehensive Language Functioning

A general estimate of intelligence and comprehensive language abilities was obtained by administration of the Peabody Picture Vocabulary Test, Form A, (PPVT) to all subjects. Permission for testing was obtained from parents of all involved subjects. The PPVT (Dunn, 1965) provides an estimate of verbal intelligence by measuring the subject's hearing vocabulary and correlates relatively well (high .70's to low $.80 ' \mathrm{~s})$ with the I.Q. scores from the Wechsler Intelligence Scale for Children (Buros, 1965). Scores on the PPVT obtained in testing within the last 6 months by speech clinicians or school psychologists were utilized if they were available for an individual child. Those individuals scoring 85 and above were considered to be functioning with intellectual and comprehensive language abilities acceptable for purposes of this study.

\section{Articulation}

The Photo Articulation Test (PAT) (Pendergast et al., 1969) was administered to potential subjects in the experimental and normal control samples. The PAT was not administered to the pre-diagnosed dyspraxics as it was assumed by the definition of dyspraxia that these individuals had an articulation disorder. Speech clinicians were consulted to determine if an experimental subject produced errors in syllables, words or in conversation.

"Severe" functional articulation cases were then select- 
ed on the basis of two criteria:

1. The subject misarticulated four or more phonemes, consistently or inconsistently, in isolation, words, syllables or in conversation. Jordon (1969) found that number of defective sounds correlated more highly with judged severity of defectiveness than other measures. A study conducted by Cohen and Diehl (1963) supported five or more error sounds as the number necessary for defining an individual as a severe functional articulation disorder. Several others (Kronvall and Diehl, 1954; Prins, 1962; Jenkins and Lohr, 1964), however, supported the selection of four sounds in error as an adequate dividing line between severe and not severe.

2. Progress in correction of speech errors was extremely slow or difficult. These individuals represented those functional articulation cases in the speech clinician's caseload who "just didn't seem to be getting anywhere."

The normal control subjects who were chosen did not evidence any articulation errors on the PAT. Their teachers reported they made no errors in syllables, words or conversation.

The neurologically impaired dyspraxic subjects used as controls in this investigation were selected from individuals referred to the University of Oregon Medical School, and diagnosed prior to this study as displaying dyspraxia of speech or verbal dyspraxia. The identification of the communication problem as dyspraxia of speech was made by three staff consultants in speech pathology after examination of speech and 
language functions. Seientific study would have been less difficult had this investigator been able to state that each of these patients had been given an unequivocal diagnosis of apraxia or dyspraxia of speech. Since, however, the diagnosis of the disorder only has appeared relatively recently in the United States, precautions were necessary to insure that those diagnosed as dyspraxic indeed demonstrated characteristics of that disorder. Folders of possible subjects for the study were examined closely. From them were formulated lists of "descriptors," terms used in the written diagnosis to denote the disorder. Frequency of occurrence of each descriptor was calculated. The ten descriptors used most often were randomized, and presented to three staff members at the Crippled Children's Division who were speech pathologists holding the $\mathrm{Ph} . \mathrm{D}$. degree in speech pathology and audiology. These individuals ranked the ten descriptors according to the order they felt best described "dyspraxia of speech." The top five descriptors provided by these persons were used in conjunction with lists of descriptors from the literature (Darley, 1968; Chappell, 1973; Yoss, 1974) to confirm characteristics of a dyspraxic disorder which were then utilized in subject selection. (See Appendix D.)

Folders of possible subjects for this study were then examined by this investigator to locate the presence of these descriptive terms. Subjects who had been diagnosed using these descriptors were chosen to serve as part of the dyspraxic control sample. 
Other Variables

Chronological age was determined from the cumulative or speech folders for each child. Additionally, each folder was examined to rule out the presence of any physical disorder which accounted for an articulation disorder, such as cleft palate or cerebral palsy. Speech clinicians provided individuals for the experimental group who had not been enrolled in speech intervention for one year or more as a functional articulation disorder.

\section{Administration of the Test Battery}

This investigator devised the battery utilized in this study (see Appendix E) by combining portions of a battery to test for dyspraxia in children (Yoss, 1973a) and a battery developed for clinical testing for apraxia in adults (Wertz and Rosenbek, 1970). It includes a verbal section and a nonverbal section.

Areas tested by this battery are:

1. Vowel Production. This subtest is composed of production of the vowel sounds $/ a /, / i /$ and $/ u /$. The examinee is instructed to "hold" each vowel for as long as he can. This first subtest was designed to reveal any dysarthric involvement, which would be evident in an abnormal voice quality (Darley, Aronson and Brown, 1969). It also provides a dyspraxic with an initial success experience because patients with apraxia of speech misarticulate consonant sounds more often than vowel sounds (Shankweiler and Harris, 1966). 
2. Diadochokinesis. In this subtest, the examinee is instructed to produce the sound sequences of $p \wedge, p \wedge, p \wedge$,

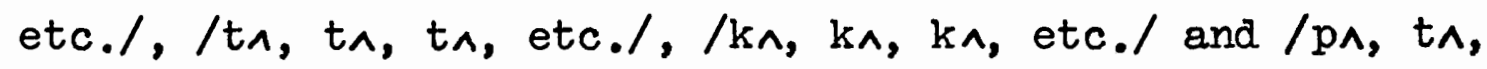
$k \wedge, p \wedge, t \wedge, k \wedge$, etc./ as fast as he can. Rosenbek (1970), working with brain-injured adults, determined the combination of the three phonemes $/ \mathrm{p} /, / \mathrm{t} /$ and $/ \mathrm{k} /$ (which appear in the battery as $/ \mathrm{p} \wedge /, / t_{\wedge} /$ and $\left./ \mathrm{k}_{\wedge} /\right)$ was an extremely sensitive task for identifying apraxia of speech.

3. Multisyllabic Words. "This task is composed of multisyllabic words containing sounds that are difficult for apraxic patients" (Wertz and Rosenbek, 1970). The examinee repeats each word after the examiner. Several studies (Shankweiler and Harris, 1966; LaPointe, 1969) have indicated that patients with apraxia of speech have problems producing fricatives, affricates and consonant clusters (i.e., sr, tr, st, etc.).

4. Words of Increasing Length. This subtest is composed of words which gradually increase in length. The examinee says each word after the examiner. ".. When phonemic composition is controlled, the patient with apraxia of speech will show more difficulty on [longer] three-syllable words than on two- or one-syllable words" (Wertz and Rosenbek, 1970). For example, of the three words "please", "pleasing", and "pleasingly", the word "pleasingly" would be expected to be the most difficult for the apraxic or dyspraxic to produce.

5. Initial-Final Phoneme Comparison. 
This task requires the examinee to produce ten words, each of which begins and ends with the same phoneme. It is expected that more errors will be noted on initial phonemes than final phonemes . . ." (Wertz and Rosenbek, 1970).

Shankweiler and Harris (1966) have stated that initial sounds as a whole are more difficult for apraxic patients than final sounds.

\section{Sentences.}

Five sentences containing sounds difficult for apraxia of speech patients and numerous multisyllabic words are presented to measure the patient's performance in connected speech (Wertz and Rosenbek, 1970).

The examinee is instructed to repeat these sentences after the examiner. More errors are expected in connected speech than in isolated words as the apraxic individual must produce more rapid and difficult changes in the placement of articulators in sequences of connected speech than is required in isolated words.

7. Spontaneous speech. In this subtest, a large "action" picture is presented to the examinee. He is instructed to tell the examiner what is happening in the picture. The first seven utterances are transcribed. This task is designed to show prosodic errors (such as inappropriate stress, rate or spacing of speech) which may appear when the apraxic individual attempts to speak spontaneously.

8. Imitative Speech. In this subtest, the examiner presents to the examinee the same seven sentences elicited spontaneously in subtest 7. The examinee repeats these sentences after the examiner. "The [apraxic client] typically 
has more difficulty on imitative tasks than on automatic reactive or spontaneous tasks .. " (Wertz and Rosenbek, 1970). One would, therefore, expect a dyspraxic individual to produce more errors on the sentences in Subtest 8 than on the same sentences as they were produced spontaneously in Subtest 7 .

9 and 10. Automatic Speech. The individual is asked to count to ten forward and backward (Subtest 9) and to say the days of the week forward and backward (Subtest 10). Wertz and Rosenbek (1970) have stated the backward performances should produce more errors than the forward, as they are less automatic.

11. Volitional Oral Movements. Yoss (1973a) indicated that oral apraxia often accompanies verbal apraxia. This test includes a set of items designed to delineate an oral apraxia (from Yoss, 1973a). The test is composed of two subsections: a) section 11a, Volịtional Oral Movements, Isolated Tasks, and b) section 11b, Volitional Oral Movements, Sequencing Tasks. In section $11 \mathrm{a}$, fourteen items are presented to the child first with auditory input only (i.e., the examiner tells the child what to do). If the correct response is not produced, a visual demonstration is then provided with the instructions to watch the examiner closely (i.e., the examiner tells and shows the child what to do). The child is presented with several tasks requiring movements of the oral structures. In section 11b, the child is instructed to put oral volitional movements together. Three 
two-item tasks and three three-item tasks are presented with visual and auditory input combined. Two trials are allowed.

12. Iimb Apraxia. The last ten items attempt to determine the presence or absence of an associated limb apraxia. Instructions are presented first with auditory input only, then paired with a visual stimulus if the subject does not respond correctly with auditory stimuli only. The child is instructed to perform several tasks requiring movements of the limbs.

AII items on the Modified Apraxia Battery (NiAB) were scored with a plus $(+)$ if the item was produced correctly and a minus ( $(-)$ if it was produced incorrectly (see Appendix F for scoring criteria).

All subjects were tape recorded during administration of the test battery using a UHER Model 4,000 tape recorder, the accompanying microphone, and laboratory standard, Realistic, 1.0 millimeter polyester recording tape. Assignment of a plus or minus value for each item on the MAB was made, however, immediately upon completion of each item by the subject, rather than from the tape.

The above battery was administered to each control and experimental subject in approximately 40 minutes. Testing time with each normal and functional articulation subject totaled approximately 60 minutes with administration of the hearing screening, PPVT, PAT and $\mathrm{PAB}$ which all were administered at one sitting in the order given above. Fifteen minutes less was required for each dyspraxic as the PAT was not 
administered to individuals in this group. If a child did not meet the required criteria on any one of the tests, testing was terminated prior to administration of the MAB.

\section{Examiner}

The examiner was a pre-Master's student in speech pathology and audiology with over 400 supervised practicum hours in diagnosis and treatment of a variety of speech disorders.

\section{Data Analysis}

Means and standard deviations were calculated for the performance of all three research groups on the total Modified Apraxia Battery, the verbal section score and the nonverbal section score. One-tailed $\underline{t}$ tests were performed to compare the differences between the mean scores of the normals and dyspraxics and between the normals and functional articulation subjects. Comparisons of the mean scores of the dyspraxics and the functional articulation subjects were performed using a two-tailed $\underline{t}$ test.

An item analysis was done using the chi square test with the Yate's correction factor, to determine the significance of the differences among the performances of the three groups. 


\section{CHAPTER IV}

\section{RESULTS AND DISCUSSION}

\section{Results}

The purpose of this investigation was to determine if children labeled as "severe" functional articulation disordered, who had been enrolled in public school speech programs for one year or more, exhibited dyspraxic-like characteristics.

Intergroup comparisons using a one-tailed $\underline{t}$ test were made between the mean scores of the normals and the severe functional articulation subjects and between the normals and the dyspraxics. A two-tailed $\underline{t}$ test comparison was made between the means of the severe functional articulation subjects and the dyspraxics. Comparisons of the means between all groups were made on the verbal section, the nonverbal section and the total Modified Apraxia Battery (MAB).

Comparisons, using $\underline{t}$ tests, made between the normal group and the functional articulation group resulted in $\underline{t}$ values of $6.7039(p<.005)$ on the verbal section, 1.555 (nonsignificant) on the nonverbal section and $5.096(\mathrm{p}<.005)$ on the total battery (Table I). These results suggest a highly, statistically significant difference in performance between normals and "severe" functional articulation disordered 


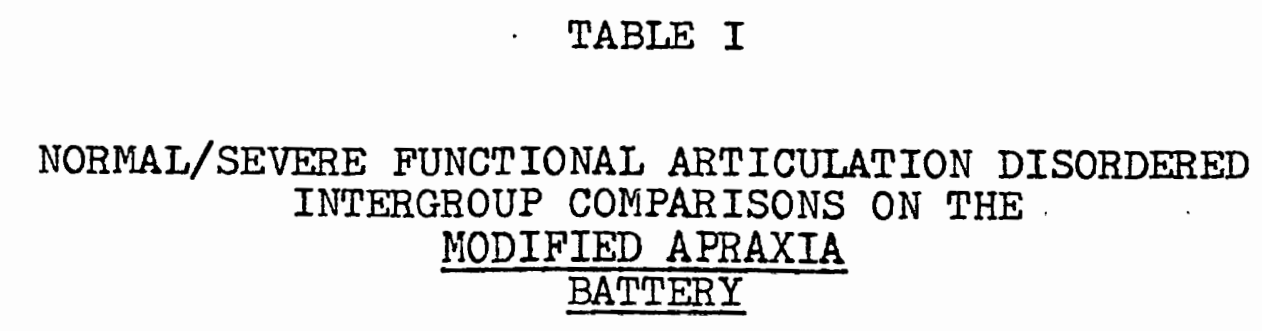

\begin{tabular}{|c|c|c|c|c|}
\hline $\begin{array}{l}\text { Test } \\
\text { Section }\end{array}$ & Groups & Mean & S.D. & $\underline{t}$ \\
\hline \multirow{2}{*}{$\begin{array}{l}\text { Verbal } \\
\text { Section }\end{array}$} & $\begin{array}{l}\text { Normal } \\
(\mathrm{N}=8)\end{array}$ & 85.00 & 3.70 & \multirow{2}{*}{$6.7039 *$} \\
\hline & $\begin{array}{l}\text { Functional } \\
\text { Articulation } \\
(N=8)\end{array}$ & 67.00 & 6.63 & \\
\hline \multirow{2}{*}{$\begin{array}{l}\text { Nonverbal } \\
\text { Section }\end{array}$} & Normal & 52.25 & 2.71 & \multirow{2}{*}{1.555} \\
\hline & $\begin{array}{l}\text { Functional } \\
\text { Articulation }\end{array}$ & 48.38 & 6.50 & \\
\hline \multirow{2}{*}{$\begin{array}{l}\text { Total } \\
\text { Battery }\end{array}$} & Normal & 137.25 & 5.56 & \multirow{2}{*}{$5.096 *$} \\
\hline & $\begin{array}{l}\text { Functional } \\
\text { Articulation }\end{array}$ & 115.13 & 10.96 & \\
\hline
\end{tabular}

$\because p<.005$ 
children on the verbal section (requiring production of words and sentences verbally) and the total battery, with the normals performing better. The performance of the two groups was not significantly different, however, on nonverbal tasks (i.e., isolated and sequenced oral volitional movements designed to delineate an oral apraxia and items requiring placement of the limbs for certain gestures, designed to deIineate a Iimb apraxia).

The $\underline{t}$ test comparisons between the normal subjects and the dyspraxic subjects resulted in a $t$ value on the verbal section of $4.0459(p<.005)$, a $t$ value on the nonverbal section of 1.115 (nonsignificant) and $a \underline{t}$ value on the total battery of $2.797(p<.01)$. Table II illustrates the mean scores, standard deviations and $t$ values for the normals and dyspraxics. A highly significant difference $(p<.005)$ in performance was shown between the normals and the dyspraxics on the verbal section of the Modified Apraxia Battery, with the normals performing better. A significant $(p<.01)$ difference was also revealed on the total battery while no statistically significant difference was evident on the nonverbal portion.

Comparisons between the dyspraxic subjects and the functional articulation group, using a two-tailed $\underline{t}$ test, resulted in $\underline{t}$ values of 1.166 (nonsignificant) on the verbal section, 2.16 (nonsignificant) on the nonverbal section and 1.86 (nonsignificant) on the total battery (Table III). No statistically significant difference, therefore, was found 


\section{TABLE II}

NORMAI/PRE-DIAGNOSED DYSPRAXIC

INTERGROUP COMPARISONS ON THE

MODIFIED APRAXIA

BATTERY

\begin{tabular}{|c|c|c|c|c|}
\hline $\begin{array}{l}\text { Test } \\
\text { Section }\end{array}$ & Groups & Mean & S.D. & $\underline{t}$ \\
\hline \multirow{2}{*}{$\begin{array}{l}\text { Verbal } \\
\text { Section }\end{array}$} & $\begin{array}{l}\text { Normal } \\
(N=8)\end{array}$ & 85.00 & 3.70 & \multirow{2}{*}{$4.0459 *$} \\
\hline & $\begin{array}{l}\text { Dyspraxic } \\
(N=4)\end{array}$ & 71.50 & 6.14 & \\
\hline \multirow{2}{*}{$\begin{array}{l}\text { Nonverbal } \\
\text { Section }\end{array}$} & Normal & 52.25 & 2.71 & \multirow{2}{*}{1.115} \\
\hline & Dyspraxic & 53.75 & 1.89 & \\
\hline \multirow{2}{*}{$\begin{array}{l}\text { Total } \\
\text { Battery }\end{array}$} & Normal & 137.25 & 5.56 & \multirow{2}{*}{$2.797 *$} \\
\hline & Dyspraxic & 125.25 & 7.63 & \\
\hline
\end{tabular}


DYSPRAXIC/SEVERE FUNCTIONAL ARTICULATION DISORDERED INTERGROUP COMPARISONS ON THE

MODIFIED APRAXIA

BATTERY

\begin{tabular}{|c|c|c|c|c|}
\hline $\begin{array}{l}\text { Test } \\
\text { Section }\end{array}$ & Groups & Mean & S.D. & $\underline{t}$ \\
\hline \multirow{2}{*}{$\begin{array}{l}\text { Verbal } \\
\text { Section }\end{array}$} & Dyspraxic & 71.50 & 6.14 & \multirow{2}{*}{$1.166 *$} \\
\hline & $\begin{array}{l}\text { Functional } \\
\text { Articulation }\end{array}$ & 67.00 & 6.63 & \\
\hline \multirow{2}{*}{$\begin{array}{l}\text { Nonverbal } \\
\text { Section }\end{array}$} & Dyspraxic & 53.75 & 6.50 & \multirow{2}{*}{$2.16 *$} \\
\hline & $\begin{array}{l}\text { Functional } \\
\text { Articulation }\end{array}$ & 48.38 & 1.89 & \\
\hline \multirow{2}{*}{$\begin{array}{l}\text { Total } \\
\text { Battery }\end{array}$} & Dyspraxic & 125.25 & 7.63 & \multirow{2}{*}{$1.86 *$} \\
\hline & $\begin{array}{l}\text { Functional } \\
\text { Articulation }\end{array}$ & 115.13 & 10.96 & \\
\hline
\end{tabular}

* nonsignificant 
between the performances of dyspraxics and the functional articulation subjects on either section of the MAB or the total battery.

Chi square analysis of verbal items on subtests 1 through 10 and nonverbal items on subtests 11 through 12 on the MAB (Appendix E) shows statistically significant differences in performance between groups (Table IV). Eight verbal items ( $3 a, 3 b, 3 e, 3 f, 6 a, 6 c, 6 d$, and 6e) demonstrated statistically significant differences between the normal and functional articulation groups. Only two nonverbal items (11a-3 and 11a-4) differentiated these two groups with statistical significance.

Four verbal items $(3 b, 6 c, 6 d$ and $6 e)$ and three nonverbal items (12-7, 12-9, 12-19) significantly differentiated the normals from the dyspraxics. Only two verbal items ( $3 f$, 6e) significantly differentiated dyspraxics from the functional articulation group, while five nonverbal items (11à-5, $11 a-14,11 b-11,12-9$ and 12-19) demonstrated statistically significant differences between these two groups of subjects.

\section{Discussion}

For this investigation four hypotheses were formulated. Hypothesis number one stated: There will be a statistically significant difference in the scores on the items of the Modified Apraxia Battery between the "severe" functional articulation disordered subjects and the normal subjects. From the results of $\underline{t}$ tests applied to the means of the normals 


\section{SIGNIFICANT ITEMS ON THE MODIFIED APRAXIA BATTERY \\ (AP PENDIX E)}

\begin{tabular}{|c|c|c|c|c|}
\hline \multicolumn{2}{|r|}{ Item } & $\begin{array}{l}t \\
x_{N}^{2}\end{array}$ & ${ }^{t} x^{2}$ & $f \quad x^{2}$ \\
\hline & \multicolumn{4}{|c|}{ Verbal Section } \\
\hline $3 a$ & "gingerbread" & $4.65 *$ & & \\
\hline $3 \mathrm{~b}$ & "artillery" & $6.25 *$ & $5.18 *$ & \\
\hline $3 e$ & "catastrophe" & $6.67 * 2$ & & \\
\hline $3 f$ & "television" & $4.06 *$ & & $5.19 *$ \\
\hline $6 \mathbf{a}$ & $\begin{array}{l}\text { "Please put the groceries } \\
\text { in the refrigerator." }\end{array}$ & $6.67^{*}$ & & \\
\hline $6 c$ & $\begin{array}{l}\text { "In the summer they sell } \\
\text { vegetables." }\end{array}$ & $9.14 * 2 *$ & $5.18 *$ & \\
\hline $6 d$ & $\begin{array}{l}\text { "The valuable watch was } \\
\text { missing." }\end{array}$ & $6.25 *$ & $5.18 *$ & \\
\hline $6 e$ & $\begin{array}{l}\text { "The shipwreck washed up } \\
\text { on the shore." }\end{array}$ & $12.25 * * 4$ & $4.50 \%$ & $6.68 *$ \\
\hline
\end{tabular}

Nonverbal Section

\begin{tabular}{|c|c|c|c|c|}
\hline $11 a-3$ & $\begin{array}{l}\text { "Show me how you would } \\
\text { whistle " (aud only) }\end{array}$ & $5.14 *$ & & \\
\hline $11 a-4$ & $\begin{array}{l}\text { "Show me how you would } \\
\text { whistle." (Aud. \& Visual) }\end{array}$ & $5.14^{*}$ & & \\
\hline $11 a-5$ & $\begin{array}{l}\text { "Touch the tip of your } \\
\text { nose with your tongue." } \\
\text { (Aud only) }\end{array}$ & & & $5.67 *$ \\
\hline $11 a-14$ & $\begin{array}{l}\text { "Wag your tongue from side } \\
\text { to side." (Aud. \& Visual) }\end{array}$ & & & $5.67^{*}$ \\
\hline $11 b-11$ & $\begin{array}{l}\text { Kiss, click tongue, stick } \\
\text { out tongue (Aud. \& visual) }\end{array}$ & & & $9.08 * * *$ \\
\hline $12-7$ & $\begin{array}{l}\text { "Threaten someone with } \\
\text { your hand. (Aud. only) }\end{array}$ & & $5.19^{*}$ & \\
\hline $12-9$ & $\begin{array}{l}\text { "Show that you are hungry." } \\
\text { (Aud, only) }\end{array}$ & & $5.19^{*}$ & $5.19^{*}$ \\
\hline $12-19$ & $\begin{array}{l}\text { "Indicate that someone is } \\
\text { crazy." (Aud. only) }\end{array}$ & & $7.24 * *$ & $9.38 *$ \\
\hline
\end{tabular}

$\dagger_{\mathrm{N}=\mathrm{Normal}}$

$F A=$ Functional Articulation

$\mathrm{D}=$ Dys praxic

$$
\begin{array}{rl}
* & p<.05 \\
* * & p<.01 \\
* * * & p<.005
\end{array}
$$


and the functional articulation group (Table I), it was concluded there was a statistically significant difference between the two groups on the verbal section of the MAB and on the total battery, but not on the nonverbal section. The first hypothesis, therefore, was supported for the verbal section and the total battery but was rejected for the nonverbal section.

The performance of the normal subjects revealed fewer errors in articulation and related verbal skills (verbal section $\bar{X}=85.00$ ) than did the performance of the functional articulation group (verbal section $\bar{x}=67.00$ ). The difference in performance on the verbal section was to be expected as the normal group, by definition, had no speech or Ianguage disorder while the functional articulation group, by definition, had severe articulation problems. The functional articulation subjects in this study performed in much the same manner as the normal subjects on the nonverbal section of the battery. Statistically, these findings do not support the results of Yoss's (1973a) study which suggest functional articulation disordered subjects perform more poorly than normal subjects on Volitional Oral Novements, particularly the sequencing tasks (Appendix E, items 11a and 11b). The functional articulation subjects in the present study, however, performed more poorly than normals. The trend established by the direction of the difference in the two groups, therefore, though not statistically significant, tends to support Yoss's findings. The significant difference in per- 
formance, between the two groups, on the total battery is: inferred to have been primarily a result of the statistically significant difference in the means on the verbal section only.

Hypothesis number two stated: There will be no statistically significant difference in the scores on the items of the Modified Apraxia Battery between the "severe" functiona? articulation disordered subjects and the "pre-diagnosed" dyspraxics. The $\underline{t}$ test results of comparisons between the means of the functional articulation group and the dyspraxics suggest there was no significant difference in performance on the Modified Apraxia Battery between these two groups. These findings indicate functional articulation disordered subjects do evidence behaviors characteristic of dyspraxia of speech. It should be noted, however, that dyspraxics did produce fewer errors (verbal section $\bar{X}=71.50$, S.D. $=6.14$ ) than did the functional articulation group (verbal section $\bar{X}=67.00$, S.D. 6.63). One would have expected the control dyspraxics to have experienced the most difficulty on the MAB as it was designed to delineate dyspraxia. The small number of the dyspraxic sample in this study may not have been representative of the total population of dyspraxics. It must be noted this difference in performance is merely a trend and not a statistically significant result. Based on the above results hypothesis number two was supported for the entire MAB.

Hypothesis number three stated: There will be a statistically significant difference in the scores on the items of 
the Modified Apraxia Battery between the "pre-diagnosed" dyspraxic subjects and the normal subjects. A highly significant difference in the performance of the dyspraxics and normals was shown on the verbal section of the MAB and on the total battery, but was not evident on the nonverbal section. As would be expected, normals produced fewer errors on the verbal section $(\bar{X}=85.00)$ than did the dyspraxics $(\bar{X}=71.50)$. The same trend was seen on the total battery (normals $\bar{X}=$ 137.25; dyspraxics $\bar{X}=125.25$ ).

Nonsignificant $\underline{t}$ values on the nonverbal section suggest the dyspraxics in this study did not evidence oral apraxia. This finding does not support the research findings of Head (1963), Darley (1968) and LaPointe (1969) who indicated an oral apraxia often accompanies an apraxia or dyspraxia of speech.

Hypothesis number three, therefore, was supported for. the verbal section of the MAB and the total battery but was rejected for the nonverbal section.

Hypothesis number four stated: Particular items on the Modified Apraxia Battery will significantly differentiate those displaying dyspraxic-like characteristics from those who do not. Chi square analysis of items on the MAB revealed statistically significant differences in performances between groups (Table IV). Hypothesis number four was, therefore, supported.

Twelve items on the verbal section significantly separated the normals from the functional articulation group and 
the dyspraxics, while only two items significantly separated the dyspraxics from the functional articulation subjects (Table IV). Six verbal items $(2 b, 2 c, 3 d, 4 h, 3 e$ and $6 a)$ approached the .05 level of significance in separating normals from dyspraxics and severe functional articulation subjects (Table V). It may be concluded the verbal section differentiated normals from dyspraxics and functional articulation. subjects. Five items significantly differentiated the normals from the dyspraxics and functional articulation groups on the nonverbal section (Table IV) and eight items approached significance in making this differentiation (Table VI); additionally, five items on the nonverbal section significantly separated dyspraxics from functional articulation subjects (Table IV) and eight nonverbal items approached significance (Table IV). Item analysis suggests the nonverbal section may separate normals from dyspraxics and functional articulation subjects. It apparently also separated dyspraxics from functional articulation subjects. Examination of the direction of performance on these items reveals the dyspraxics performed better than both the normals and the functional articulation subjects on discriminating items. This suggests either that the dyspraxic sample in this investigation did not exhibit an oral apraxia or that the normals and functional articulation subjects did exhibit an oral apraxia.

one would have expected the normal subjects, by definition, to perform with the least number of errors on all 
VERBAL SECTION ITEMS APPROACHING SIGNIFICANCE

AT THE .05* LEVEI ON THE

MODIFIED APRAXIA

BATTERY

\begin{tabular}{|c|c|c|c|c|}
\hline \multicolumn{2}{|r|}{ Item } & $t_{N} x^{2} F A$ & $+\frac{x^{2}}{N}$ & $D / F A$ \\
\hline 1c & $\begin{array}{l}\text { "Say oo and hold it as } \\
\text { long as you can." }\end{array}$ & & & 3.41 \\
\hline $2 \mathrm{~b}$ & $\begin{array}{l}\text { "Say tuh-tuh-tuh-tuh-tuh- } \\
\text { tuh." }\end{array}$ & 2.4 & & \\
\hline $2 c$ & $\begin{array}{l}\text { "Say kuh-kuh-kuh-kuh-kuh- } \\
\text { kuh." }\end{array}$ & 2.4 & & \\
\hline $3 a$ & "gingerbread" & & & \\
\hline $3 c$ & "snowman" & & & \\
\hline $3 \mathrm{~d}$ & "impossibility" & 2.25 & & \\
\hline $3 e$ & "catastrophy" & & 3.38 & \\
\hline $4 e$ & "zipper" & & & 3.41 \\
\hline $4 g$ & "pleasing" & & & 3.68 \\
\hline $4 \mathrm{~h}$ & "pleasingly" & 2.4 & & \\
\hline $5 c$ & "sis & & & 3.41 \\
\hline $5 g$ & "shush" & & & 3.41 \\
\hline $6 a$ & $\begin{array}{l}\text { "Please put the groceries } \\
\text { in the refrigerator." }\end{array}$ & & 3.38 & \\
\hline 8 & $\begin{array}{l}\text { "Now I want you to repeat } \\
\text { your sentences after me. }\end{array}$ & & & 3.41 \\
\hline
\end{tabular}

$t_{\mathrm{N}=\text { Normals }} t_{\mathrm{FA}}=$ Functional Articulation

$t_{D}=$ Dyspraxics

$* p=.05=3.84$ 
NONVERBAL SECTION ITEMS APPROACHING SIGNIFICANCE AT THE .05* LEVEL ON THE MODIFIED APRAXIA BATTERY

\begin{tabular}{|c|c|c|c|c|}
\hline & Item & $t_{N}^{t} x^{2} F A$ & $+x^{2}$ & $t_{D}^{t} x^{2}$ \\
\hline $11 a-3$ & $\begin{array}{l}\text { "Show me how you would whis- } \\
\text { tle," (Aud. only) }\end{array}$ & & 3.68 & \\
\hline $11 a-4$ & $\begin{array}{l}\text { "Show me how you would whis- } \\
\text { tle." (Aud. \& Visual) }\end{array}$ & & 3.68 & \\
\hline $11 a-5$ & $\begin{array}{l}\text { "Touch the tip of your nose } \\
\text { with your tongue." (Aud. } \\
\text { only) }\end{array}$ & 3.0 & & \\
\hline $11 a-6$ & $\begin{array}{l}\text { "Touch the tip of your nose } \\
\text { with your tongue." (Aud. \& } \\
\text { Visual) }\end{array}$ & & & 3.68 \\
\hline $11 a-9$ & $\begin{array}{l}\text { "Show me how your teeth } \\
\text { chatter when you're cold." } \\
\text { (Aud only) }\end{array}$ & & & 3.68 \\
\hline $11 a-13$ & $\begin{array}{l}\text { "Wag your tongue from side } \\
\text { to side." (Aud, only) }\end{array}$ & & 3.41 & 3.68 \\
\hline $11 a-14$ & $\begin{array}{l}\text { "Wag your tongue from side } \\
\text { to side." (Aud. \& Visual) }\end{array}$ & & & 3.41 \\
\hline $11 a-16$ & $\begin{array}{l}\text { "Click or pop your tongue." } \\
\text { (Aud. \& Vi-sual) }\end{array}$ & & & 3.41 \\
\hline $11 a-17$ & $\begin{array}{l}\text { "Puff out your cheeks." } \\
\text { (Aud. only) }\end{array}$ & & 3.41 & \\
\hline $11 a-19$ & "Blow." (Aud, only) & & & 3.41 \\
\hline $11 a-22$ & $\begin{array}{l}\text { "Clear your throat." } \\
\text { (Aud. \& Visual) }\end{array}$ & & & 3.41 \\
\hline $11 a-26$ & $\begin{array}{l}\text { "Lick your Iips all the way } \\
\text { around." (Aud, \& Visual) }\end{array}$ & & & 3.68 \\
\hline$\overline{11 b-7}$ & $\begin{array}{l}\text { Click teeth (chatter), Iick } \\
\text { lips, clear throat. (First } \\
\text { attempt) }\end{array}$ & & 3.41 & 3.68 \\
\hline $11 b-8$ & $\begin{array}{l}\text { Click teeth (chatter), lick } \\
\text { lips, clear throat. (Second } \\
\text { attempt) }\end{array}$ & & 3.41 & 3.41 \\
\hline $11 b-12$ & $\begin{array}{l}\text { Kiss, click tongue, stick } \\
\text { out tongue. (Second attempt) }\end{array}$ & & & 3.38 \\
\hline $12-1$ & $\begin{array}{l}\text { "Show how to salute." } \\
\text { (Aud. only) }\end{array}$ & & 3.41 & 3.68 \\
\hline$\overline{12-17}$ & $\begin{array}{l}\text { "Show how to sharpen a pen- } \\
\text { cil." (Aud. only) }\end{array}$ & & & 3.41 \\
\hline $12-20$ & $\begin{array}{l}\text { "Indicate that someone is } \\
\text { crazy." (Aud. \& Visual) }\end{array}$ & & & 3.41 \\
\hline
\end{tabular}

FN=Normals +FA=Functional Articulation $+D=D y$ spraxic 
portions of a test whioh validly discriminates those manifesting dyspraxic-like characteristics from those who do not. Chi square analyses suggest, therefore, that any significant difference in performance on nonverbal items between the dyspraxics and functional articulation group may have been a test artifact due to the small number of subjects involved. Item 1c approached significance in discriminating dyspraxics from functional articulation subjects. Items $2 \mathrm{~b}$ and 2c approached significance in aiscriminating normals from functional articulation subjects. More functional articulation subjects made errors on 1c (Vowel Production, producing $\mathrm{lu} /$ for as long as possible) than dyspraxics. On items $2 \mathrm{~b}$ (Diadochokinesis, say tuh-tuh-tuh-tuh-tuh-tuh) and $2 c$ (Diadochokinesis, say kuh-kuh-kuh-kuh-kuh-kuh), functional articulation subjects produced more errors than normals. AIthough these items ( $2 b$ and $2 c$ ) were not statistically significant, the trend established tends to support Yoss (1972) who stated dyspraxics produce below average scores on measures of oral diadochokinesis. The same result would be expected for the functional articulation group. It is important to note that all three groups experienced difficulty in production of diadochokinetic sequences. This may partially account for a lack of statistically significant differentiation among the groups on this item, as the normal subjects may not have been entirely "normal" in production of sequenced phonemes.

Subsection 3, Multisyllabic Words, appeared to be a 
discriminating verbal subsection (see Tables IV and V). The dyspraxic and functional articulation subjects tended to perform alike on this item, while both performed poorer than the normals. Errors made by all three groups, included misarticulations of fricatives, affricates and consonant clusters, the sounds indicated by Shankweiler and Harris (1966) and LaPointe (1969) as being especially difficult for individuals with an apraxia of speech. Other phonemic errors occurred particularly on $/ 1 /, / r /$ and $/ x /$. The most errors were made by the functional articulation group followed by the dyspraxics and the normals. The greatest number of errors made by all three groups tended to be substitutions, followed in frequency of occurrence by omissions, transpositions of sounds or syllables, distortions and additions. Several authors (Darley, 1968; Johns, 1968; Deal, 1970; Johns, 1970; Johns and Darley, 1970; Wertz et al., 1970; Rosenbek et al., 1973) reported adult apraxics evidence prominent phonemic errors such as omissions, substitutions, distortions, additions and repetitions. The above findings of this study also support similar results presented by Yoss (1973a). Yoss (1972) reported that, with dyspraxic children, repetitions of combined syllables (i.e., polysyllabic words) are often produced with incorrect syllable order. Results noting transposition of syllables by individuals in this study support Yoss's findings. Errors occurred almost exclusively on syllables following the first two syllables in polysyllabic words. These characteristics in children are 
similar to those in adults which suggest these individuals experience increasing articulatory difficulty as word length increases (Darley, 1964; Darley, 1968; Johns, 1970; Johns and Darley, 1970; Wertz et al., 1970; Deal and Darley, 1972; Edwards, 1973; and Rosenbek et al., 1973). Blakeley (1972) speaking specifically of children also suggested that the longer the word, the greater the difficulty the dyspraxic would experience in producing it correctly. It would seem, then, that words of increasing length are difficult for both dyspraxic children and apraxic adults.

Vowels on the MAB were rarely misarticulated. These results support prior findings by Shankweiler and Harris (1966), LaPointe (1969) and Yoss (1972) indicating there is generally a marked integrity of vowels with dyspraxia or apraxia of speech.

Perseveration of a sound into several adjoining syllables was noted in the productions of one individual from the functional articulation disordered group. For example, "catastrophe" was produced as /kofxftoufi/. Darley, (1968), Johns (1968) and Johns and Darley (1970) have suggested the speech of apraxic adults may show perseveration on phonemes, syllables, words or phrases. The data on this one child possibly suggest the perseveration may also be evident in children.

Interestingly, individuals in all groups who misarticulated a particular word on the first attempt, many times produced the word correctly on a second or third attempt. Johns 
and Darley (1970) and Edwards (1973) reported with adult apraxics, speech improves when the individual is allowed to make several consecutive attempts to produce a desired response. Yoss (1973b) reiterated these off-target "trial and. error" attempts also are frequent in children.

Subsection 4, Words of Increasing Length, involved the production of words which were controlled in phonemic context, but which increased in length from a single syllable to a three-syllable utterance. An example is "jab", "jabber", "jabbering". Although no particular subsections significantly separated group performances, some items did approach significance (see Table V). It was this investigator's clinical impression that items $4 \mathrm{~g}$ and $4 \mathrm{~h}$ ("please.", "pleasing", "pleasingly") support a trend suggesting words of increasing length are difficult.

Subsection 5, Initial-Final Phoneme Comparison, was designed to discover any problem in initiation of words. Shankweiler and Harris (1966), Darley (1968) and LaPointe (1969) speaking of adults, and Rosenbek (1974) discussing children, have contended that initiation of utterances is frequently very difficult, more so than production of the same phonemes in the final position. In this investigation, this contention was not supported, as initial sounds in all groups were consistently produced in the same manner as or in a superior manner to the final sound.

Subsection 6, Sentences, proved to be one of the most discriminating portions of the verbal section (see Tables IV 
and $V$ ). As on subsection 3, the dyspraxics and functional articulation subjects tended to perform alike, while both groups performed poorer than the normals. These sentences containing numerous difficult sounds and multisyllabic words were designed to measure performance in connected speech. Several authors have noted that in less severe cases of dyspraxia, articulatory inaccuracies occur mainly during conversational speech, production of polysyllabic or motorically complex words (Blakeley, 1972; Yoss, 1972; Rosenbek, 1974; and Yoss, 1974). Johnson and Myklebust (1967) and Blakeley (1972) stated these children often produce consonants correctly in isolation, but have difficulty in making the necessary movement sequences for adding vowels to consonants. Connected speech hypothetically would reveal errors, then, which single-word tasks might not.

This investigator noted in administration of the Photo Articulation. Test (Pendergast et al., 1969) far fewer errors were produced by the dyspraxics and functional articulation group than were seen later in production of words in subsections 3 through 5, and in production of sentences in subsection 6. Normals performed significantly better on subsection 6, as a whole, than did either the dyspraxic or functional articulation subjects. The performances of the latter two groups resembled one another. Subsection 6, Sentences, may be assumed, therefore, to be a sensitive item for differentiating those displaying dyspraxic-like characteristics from those who do not. 
Subsection 7, Spontaneous Speech, designed to show prosodic errors in spontaneous speech and subsection 8 , Imitative Speech, designed to compare difficulty in production of imitative versus spontaneous speech, did not make any significant differentiations among groups. Only one individual, a pre-diagnosed dyspraxic, evidenced prosodic problems. His behavior represented the contention of several authors (Shankweiler and Harris, 1966; Darley, 1968; Johns and Darley, 1970; Wertz et al., 1970; and Yoss, 1972) that in both adults and children, anticipation of errors and attempts to produce clearer speech result in slowed rate, even stress and even spacing. No other individuals demonstrated these prosodic disturbances in spontaneous speech; however, with a larger number of subjects in the study, this may have been more evident.

Imitative speech, represented by subsection 8, was generally produced better than spontaneous speech. These results do not support contentions of several authors that imitative ability is generally poor (Head, 1963; Ingram, 1964; Johnson and Myklebust, 1967; Darley, 1968; Johns and Darley, 1970; Wertz et al., 1970; and Chappell, 1973).

According to Wertz (1970) and Rosenbek (1973), less automatic speech (subsections 9 and 10) will be misarticulated more often than automatic speech. This pattern was not supported in this study. These two verbal subsections resulted in no statistically significant differentiations among groups. Subsections 11 and 12, forming the nonverbal section of 
the MAB contained several items which significantly differentiated groups. Most of these differentiations, however, were between dyspraxics and functional articulation disordered subjects. It has been theorized any significant difference between these two groups may be a test artifact produced by the small numbers of subjects involved in this investigation. Particular items of subsections 11 and 12 will not be discussed, but for further information the reader is referred to Tables IV and VI.

In addition to the specific characteristics given $(+)$ or (-) values on the battery, this investigator noted some relevant behaviors not scored on the MAB.

In both single word items and sentences, it was noted that correct phoneme production and error production tended to be inconsistent for the dyspraxics. This result tends to support findings of several researchers (Darley, 1964; Shankweiler and Harris, 1966; LaPointe, 1969; Johns and Darley, 1970; Wertz et al., 1970; Fawcus, 1971; Blakeley, 1972; Yoss, 1972 ; Edwards, 1973; Rosenbek et al., 1973; and Rosenbek, 1974). Error production and correct phoneme production tended to be more consistent for the majority of functional articulation subjects. This would tend not to support a similarity in performance between the dyspraxics and severe functional articulation subjects in this study.

The individuals in all groups in this investigation seemed to be aware of their errors: Some individuals in the functional articulation and dyspraxic groups were frustrated 
by their apparent inability to correctly produce certain words. The children involved in this study are older and most have received several years of speech intervention. Apparently, these results tend to support Yoss's (1973b) statement that older children may be aware of their errors though younger ones usually are not. Adults usually know they are producing sounds incorrectly (Shankweiler and Harris, 1966; Johnson and Myklebust, 1967; Darley, 1968; Johns, 1970; Wertz et al., 1970).

According to Fay (1966) and Darley (1968), sequencing of phonemes is difficult for adults with apraxia of speech. This investigator observed that in all types of items (i.e., diadochokinesis, word production, sentence production and production of sequences of Iimb and oral structure movements) great difficulty was evident in sequencing. The functional articulation group and the dyspraxics both displayed this difficulty. The normals displayed some difficulty with sequencing of puh, tuh, kuh, but generally produced words, sentences and sequences of limb and oral structure movements with acceptable levels of ability. 


\section{CHAPTER V. \\ SUMMARY AND IMPLICATIONS}

\section{Summary}

The purpose of this investigation was to determine if children labeled as "severe" functional articulation disordered, who had been enrolled in public school speech programs for one year or more, exhibited dyspraxic-like characteristics.

Twenty individuals between the ages of 8 and 11 were chosen from the Gresham Public Schools, Lynch Public Schools, Portland Public Schools, Rockwood Public Schools and the Crippled Children's Division, University of Oregon Medical School to serve as subjects for the three groups in this study. Eight subjects who comprised the experimental group were "severe" functional articulation disorders and were selected from the public schools. Each misarticulated four or more phonemes, consistently or inconsistently, in isolation, syllables, words or conversation; each had made little or very slow progress according to his speech clinician and each had been enrolled in speech management for one year or more as a functional articulation case.

Eight subjects in the normal control group were individuals selected from the public schools, with no speech or lan- 
guage problems. Each had never been enrolled in nor recommended for a speech intervention program.

Four subjects in the dyspraxic control group were selected from the University of Oregon Medical School. Prior to the date of this investigation, each had been diagnosed as displaying developmental dyspraxia, dyspraxia of speech or verbal dyspraxia.

The Modified Apraxia Battery (MAB) utilized in this investigation was a nonstandardized battery consisting of a verbal section and a nonverbal section. The verbal section was composed of ten subtests designed to delineate the presence of a dyspraxia of speech; the nonverbal section was composed of one subtest designed to delineate an oral apraxia and one subtest designed to delineate a limb apraxia.

The results of this study revealed a highly significant difference in performance on the verbal section between the normal subjects and the "severe" functional articulation subjects with the normals performing better. A highly significant difference also was found between the normal subjects and the dyspraxic subjects with the normals performing better on the verbal section of the MAB. No significant difference was revealed, however, between the dyspraxics and the "severe" functional articulation cases. It was inferred, therefore, that these two groups performed in a similar manner because they exhibited similar verbal characteristics. "Severe" functional articulation disordered subjects were, therefore, found to exhibit verbal dyspraxic-like characteristics. 
No significant difference in performance was shown on the nonverbal section among the three groups.

It appears the verbal section of the Modified Apraxia Battery much more effectively differentiates those displaying dyspraxic-like characteristics from those who do not than does the nonverbal section. Chi square analysis of items on the MAB supported this contention further suggesting subsection 3, Multisyllabic Words and subsection 6, Sentences are the most discriminating verbal items.

\section{Implications}

\section{Clinical}

The results of this study would appear to indicate to speech clinicians, in both public school and nonpublic school settings, that the verbal portion of the MAB could be utilized to delineate those individuals in their caseloads who may exhibit dyspraxic-like characteristics. Additionally, these clinicians should familiarize themselves with characteristics of dyspraxia and intervention suggestions from the Iiterature to aid in the management of those displaying these characteristics. Clearly these individuals should be separated from true functional articulation disorders so that the most effective type of management program might be provided for each type of speech disorder.

\section{$\underline{\text { Research }}$}

This investigator suggests replication of this study 
utilizing larger samples might be valuable in order to determine if the verbal section is as effective a tool as it appeared in this study in discriminating between those displaying verbal dyspraxia and those who do not. Additionally, larger samples might reveal whether or not the nonverbal section is a valid tool to differentiate those displaying oral and limb apraxias from those who do not. The dyspraxics utilized in this investigation did not display a related oral apraxia. It was not clear, however, if this was because no dyspraxics display a related oral apraxia or if the four individuals in this study were not representative of the total population of dyspraxic individuals.

It also is suggested standardization of the entire MAB on a suitable sample of pre-diagnosed dyspraxics would be very valuable. Results of this standardization would aid speech clinicians in evaluating individuals in their caseloads against this standardized performance. Once the battery had been standardized, it would be interesting to administer it to a sample of dysarthric individuals to determine whether or not the battery effectively separates dysarthrics from dyspraxics. Likewise, it is recommended it be administered to a group of "true" functional articulation disordered subjects as the subjects in this investigation likely were not truely functional articulation disordered.

It was the clinical impression of this investigator that short term memory problems may have interfered with production of several items on the MAB by both the dyspraxic 
and functional articulation disordered subjects in this study. Further investigation of short term memory skills of these two groups as compared to normals may provide further'information relative to the role of memory problems in articulation disorders. 


\section{SELECTED BIBLIOGRAPHY}

AGRANOWITZ, A. and MCKEOWN, M. Aphasia Handbook for Adults and Children. Springfield, Ill.: Charles C. Thomas (1964).

ATEN, J.L., JOHNS, D.F. and DARLEY, F.L. Auditory perception of sequenced words in apraxia of speech. J. Speech Hearing Res., 14 (1), 131-144 (1971).

ATEN, J. and DAVIS, J. Disturbances in the perception of auditory sequence in children with minimal cerebral dysfunction. J. Speech Hearing Res., 11 (2), 236-245 (1968).

BERRY, M.F. and EISENSON, J. Speech Disorders: Principles and Practices of Therapy. New York: Appleton-CenturyCrofts $(1956)$.

BIAKELEY, R.W. The Practice of Speech Pathology, A Clinical Diary. Springfield, III.: Charles C. Thomas (1972).

BUROS, O.K. The Sixth Mental Measurements Yearbook; Highland Park, New Jersey: The Gryphon Press (1965).

CHAPPELI, G.E. Childhood verbal apraxia and its treatment. J. Speech Hearing Dis., 38 (3), 362-369 (1973).

COHEN, J.H. and DIEHL, D.F. Relation of speech sound discrimination ability to articulation-type speech defects. J. Speech Hearing Dis., 28 (2), 187-191, (1963).

DALY, D.A., CANTRELL, R.P., CANTRELI, M.L. and ANAN, L.A. Structuring speech therapy contingencies with an oral apraxic child. J. Speech Hearing Dis., 37 (1), 22-33 (1972).

DARLEY, F.I. Diagnosis and Appraisal of Communication Disorders. Englewood Cliffs, N.J.: Prentice-Hall, Foundations of Speech Pathology Series (1964).

DARLEY, F.L. Apraxia of speech: 107 years of terminological confusion. Paper presented at the annual convention of the American Speech and Hearing Association, Denver, colo. (1968) 
DARLEY, F.I. Apraxia of speech: definition, description and appraisal. Paper presented at the annual convention of the American Speech and Hearing Association, New York (1970).

DARLEY, F.I., ARONSON, A.E. and BROWN, J.R. Differential diagnostic patterns of dysarthria. J. Speech Hearing Res., 12, 246-269 (1969).

DEAI, J.L. The influence of linguistic and situational variables on the phonemic accuracy in apraxia of speech. Unpublished Ph.D. Dissertation, University of Mississippi, University, Miss. (1970).

DERENZI, E., PIECZURO, A. and VIGNOIO, A. Oral apraxia and aphasia. Cortex, 2, 50-73 (1966).

DERENZI, E. and VIGNOIO, I. The Token Test: a sensitive test to detect receptive disturbances in aphasia. Brain, 85 (5), 665-679 (1962).

- DUNN, I. Peabody Picture Vocabulary Test. Minneapolis, Minn.: American Guidance Service, Inc. (1965).

EDWARDS, M. Developmental verbal dyspraxia. British J. Communication Dis., 8 (11), 64-71 (1973).

ELIIS, E. Problems of communication in a school for children with cerebral palsy. In C. Renfrew and K. Murphy (Eds.) The Child Who Does Not Talk. London: Heinemann (1964).

EWING, A. Aphasia in Children. New York: Hafner Pub. Co. $(1967)$.

FAWCUS, R. The psychological and physiological basis of articulatory performance. British J. Communication Dis., 6 (2), 99-107 (1971).

FAY, W. Temporal Seguence in the Perception of Speech. London: Mouton and Co. (1966).

FAY, W. Notes from presentation on verbal dyspraxia, Portland State University, Jan. (1974).

FERRY, P. Verbal dyspraxia in children: a neurological cause of "poor speech". J. Oregon Speech Hearing Assoc., 13

(2), 14-19 (1974).

FLETCHER, S.G. Norms for diadochokinetic rate. Unpublished research project. Crippled Children's Division, University of Oregon Medical School, Portland, Oregon (1962). 
GATZ, A. Manters Essentials of Clinical Neuroanatomy and Neurophysiology. 4th Ed. Philadelphia: F.S. Davis Co. $(1970)$.

GORDON, N. The concept of central deafness. In C. Renfrew and $\dot{K}$. Murphy (Eds.), The Child Who Does Not Taik. London: Heinemann (1964).

HEAD, H. Aphasia and Kindred Disorders of Speech. Vol. I. New York: Hafner Pub. Co. (1963).

HEAD, H. Aphasia and Kindred Disorders of Speech. Vol. II. New York: Hafner Pub. Co. (1963).

INGRAM, T.T.S. Late and poor talkers. In C. Renfrew and K. Murphy (Eds.), The Child Who Does Not Talk. London: Heinemann $(1964)$.

JENKINS, E. and IOHR, R. Severe articulation disorders and motor ability. J. Speech Hearing Dis., 29 (3), 286293 (1964).

JOHNS, D. A systematic study of phonemic variability in apraxia of speech. Unpublished Ph.D. Dissertation, The Florida State University, Tallahasse, Florida (1968).

JOHNS, D. Application of experimental evidence in the treatment of apraxia of speech. Paper presented at the annual convention of the American Speech and Hearing Association, New York, Nov. (1970).

JOHNS, D. and DARLEY, F.I.' Phonemic variability in apraxia of speech. J. Speech Hearing Res., $13(3), 556-584$ (1970).

JOHNSON, W., DARLEY, F.L. and SPRIESTERSBACH, D.C. Diagnostic Methods in Speech Pathology. New York: Harper and ROW (1963).

JOHNSON, W., BROWN, S., CURTIS, J., EDNEY, C and KEASTER, J. Speech Handicapped School Children. 3rd Ed. New York: Harper and Row (1967).

JOHNSON, D. and MYKLEBUST, H. Learning Disabilities, Educational Principles and Practices. New York: Grune \& Stratton (1967).

JORDON, E.P. Articulation test measures and listener ratings of articulation defectiveness. J. Speech Hearing Res. , $3(4), 303-320$ (1967).

KIRK, S. Educating Exceptional Children. Boston: HoutonMiffin Co. (1962). 
KOOLS, J and TWEEDIE, D. The development of praxis in children. Paper presented at the annual convention of the American Speech and Hearing Association, Detroit, Mich. (1973).

KRONVALI. E. and DIEHL, $C$. The relationship of auditory discrimination to articulation defects of children with no known organic impairment. J. Speech Hearing Dis., 19 (3), 335-339 (1954).

IAPOINTE, L. An investigation of isolated oral movements, oral-motor sequencing abilities, and articulation of brain-injured adults. Unpublished Ph.D. Dissertation, University of Colorado, Boulder, Colo. (1969).

IAPOINTE, I. Phonemic characteristics in apraxia of speech which aid in differentiating among articulation disorders in brain-injured adults. Paper presented at the annual convention of the American Speech and Hearing Association, New York (1970).

LOCKE, J. Questionable assumptions underlying articulation research. J. Speech Hearing Dis., 33 (2), 112-117 (1968).

LUCHSINGER, R. and ARNOID, G. Voice, Speech and Language: Clinical Communicology: It s Physiology and Pathology. Belmont, Calif.: Wadsworth Pub. Co. (1965).

MARTIN, A.D. Some objections to the term "Apraxia of speech." J. Speech Hearing Dis., 39 (1), 53-56 (1974).

MCGINNIS, M. Aphasic Children, Identification and Education by the Association Method. Wash., D.C.: Alexander Graham Bell Association for the Deaf (1963).

MORLEY, M. Defects of articulation. Folia Phoniatricia., $11(1-3), 65-124$ (1959).

MORLEY, M. Prognosis in relation to developmental disorders of speech in children, based on the experience of a speech therapist. In C. Renfrew and $K$. Murphy (Eds.) The Child Who Does Not Talk. London: Heinemann (1964).

MORLEY, M. and FOX, J. Disorders of articulation, theory and therapy. British J. Communication Dis., 4 (2), 151166 (1969).

NATIONAL INSTITUTE OF NEUROLOGICAL DISEASE AND STROKE. Human Communication and Its Disorders, lionograph 10. Bethesda, Maryland: U.S. Department of Health, Education and Welfare (1970). 
NIELSEN, J. Agnosia, Apraxia, Aphasia: Their Value in Cerebral Localization. Los Angeles, Calif.: The Los Angeles Neurological Society (1936).

PENDERGAST, K., DICKEY, S., SELMAR, J. and SODER, A. Photo Articulation Test. Danville, III.: The Interstate Printers and Pubs. Inc. (1969).

PRINS, T.D. Motor and auditory abilities in different groups of children with articulatory deviations. J. Speech Hearing Res., 5 (2), 161-169 (1962).

ROBERTS, A. The Aphasic Child: A Neurological Basis for his Education and Rehabilitation. Springfield, Ill.: Charles C. Thomas (1966).

ROSENBEK, J. Oral sensation and perception in apraxic and aphasic adults. Unpublished Ph.D. Dissertation, University of Colorado, Boulder, Colo. (1970).

ROSENBEK, J., WERTZ, $R$, and DARLEY, F. Oral sensation and perception in apraxia of speech and aphasia. J.Speech Hearing Res., 16 (1), 22-37 (1973).

ROSENBEK, J., HANSEN, R., BAUGHMAN, C.H. and IEMME, M. Treatment of developmental apraxia of speech: a case study. Language, Speech and Hearing Services in the Schools, 5(1), 13-23 (1974).

SAMO, M. Aphasia, Selected Readings. New York: AppletonCentury-Crofts (1972).

SHANKWEILER, D. and HARRIS, K. An experimental approach to the problem of articulation in aphasia. Cortex, 2, 277292 (1966).

SONNINEN, A. and DAMSTE, P. An international terminology in the field of logopedics and phoniatrics. Folia Phoniatricia, 23 (1), 1-32 (1971).

VAN RIPER, C. Speech Correction: Principles and Methods. 4th Ed. Englewood Cliffs, N.J.: Prentice-Hall (1963).

WATON, J., ELIIS, E. and COURT, S.D.F. Clumsy children: a study of developmental apraxia and agnosia. Brain, 85 (3), 603-613 (1962).

WEPHAN, J. Recovery from Aphasia. New York: Ronald Press Co. (1951). 
WERTZ, R., ROSENBEK, J: and DEAL, J. A review of 228 cases of apraxia of speech: classification, etiology, and 10calization. Paper presented at the annual convention of the American Speech and Hearing Association, New York (1970).

WERTZ, R. and ROSENBEK, J. Appraising apraxia of speech. Unpublished paper (1970).

WOOD, N. Delayed Speech and Language Development. Englewood Cliff ,. N.J.: Prentice-Hall Foundations of Speech Pathology Series (1964).

YOSS, K. Developmental apraxia of speech in children with defective articulation. Paper presented at the annual convention of the American Speech and Hearing Association, San Francisco; Calif. (1972).

YOSS, K. Developmental apraxia of speech in children with defective articulation. Unpublished Ph.D. Dissertation, The Florida State University, Tallahasse, Florida (1973a).

YOSS, K. What happens to children with developmental apraxia of speech? Paper presented at the annual convention of the American Speech and Hearing Association, Detroit, Mich. (1973b).

YOSS, $K$. and DARIEY, F. Therapy in developmental apraxia of speech. Language, Speech and Hearing Services in the Schools, 5(1), 23-32 (1974). 
1. Apraxia is ". . a disruption in the ability to transmit or express a motor response along a specific modality, difficulty in the articulation of speech, in the formation of letters in writing, or in the movements of gesture and pantomime" (Wepman in Johnson and Myklebust, 1967).

2. "Apraxia is the ability to carry out voluntary movements or purposeful acts. The inability to speak is sometimes considered apraxia, but the word is usually used in reference to purposeful motor or manual gestures. In these cases the motor function is intact" (Kirk, 1962).

3. Apraxias are "... inabilities to perform purposeful skilled acts even though there is no paralysis" (Johnson, Darley and Spriestersbach, 1963).

4. "By apraxia we mean the inability to make a movement voluntarily which can otherwise be produced involuntarily" (Van Riper, 1963).

5. Apraxia "... refers to an inability to command a part of the body to make a willed movement" (Van Riper, 1963).

6. Apraxia ".. refers to an inability to act or to move various parts of the body in a purposeful manner, although the power of the movement is intact" (Johnson and Myklebust, 1967).

7. "Apraxias are disturbances characterized by disability in the voluntary and intended use of tools. When the tools are the organs of articulation, speech becomes directly affected and we have oral or verbal apraxia . . . A patient with apraxia may be able to formulate the language he wishes to evoke, but have his evocation impaired..." (Berry and Eisenson, 1956).

8. "Articulatory apraxia is ... a condition where there is inability to perform the movements required to reproduce sounds accurately (in isolation or combination) when hearing and perception are normal, and the movements as for swallowing and sucking are performed in a normal manner" (Sonninen and Damste, 1971). 


\section{APPENDIX B}

\section{CHARACTERISTICS OF APRAXIA}

1. Some speaking attempts are better than others. The apraxic produces some difficult words easily; he makes some errors on easy ones. There are islands of error-free production (Darley, 1964; Darley, 1968; Johns, 1968; IaPointe, 1969).

2. The individual cannot form necessary motor movement patterns to speak correctly. Apraxia is a disorder of motor programming (Johnson and Myklebust, 1967; Deal, 1970; Edwaras, 1973).

3. Oral apraxia often accompanies the apraxia of speech (Head, 1963; Darley, 1968; Wertz, 1970).

4. No significant weakness or paralysis of the musculature or speaking apparatus is apparent (Morley, 1959; Head, 1963; Darley, 1968).

5. The speech of an apraxic shows some of the same characteristics of stuttering; i.e., circumlocutions, substituted words, false starts, anticipation of difficulty, repetitions, blocking, perseveration on phonemes, syllables, words, and phrases (Darley, 1968; Johns, 1968; Johns and Darley, 1968).

6. There is no reduction in auditory comprehension; reception basically seems intact (Johnson and Myklebust, 1967; Johns, 1970; Edwards, 1973).

7. Errors vary with the complexity of the articulatory ad justment (Darley, 1968; Wertz, 1970).

8. Automatic-reactive speech is better than volitionalpurposive speech (Wertz, 1970; Rosenbek, 1973).

9. The sequencing of phonemes is effortful (Fay, 1966; Darley, 1968).

10. There is a certain "unrelatedness" of some substitutions; some "more difficult" blends are substituted for less difficult blends; i.e., a three phoneme blend for a two phoneme blend, etc. (Shankweiler and Harris, 1966; Johns, 1970).

11. Fricatives, affricates, and consonant clusters consistentiy are misarticulated (Shankweiler and Harris, 1966; LaPointe, 1969).

12. Frequent errors of voicing and nasalization are common (Shankweiler and Harris, 1966; Yoss, 1973).

13. Marked integrity of vowels is present (Shankweiler and Harris, 1966; LaPointe, 1969). 
14. There is significant improvement of speech if other modalities, especially vision, are utilized with the auditory. Visual monitoring benefits these persons greatly (Johns, 1970; Johns and Darley, 1970).

15. Speech improves when the individual is allowed to make several consecutive attempts to produce a desired response (Johns and Darley, 1970; Edwards, 1973).

16. Vocabulary may be limited; word finding errors occur (Darley, 1964).

17. Some errors are perseverative, others anticipatory (Wertz, 1970).

18. Speaking may be significantly poorer than other language modalities, i.e., listening, writing, gesture (Darley, 1968).

19. Many apraxics experience initiation difficulties on words; repetition of the initial sound is heard; also retrials using different sound combinations are common (Darley, 1968; LaPointe, 1969).

20. Facial grimacing is common, accompanied by silent and phonated movement of the articulators as if the individual is attempting to "set up" the sequence to follow (Johns and Darley, 1970). 
APPENDIX C

TREATMENT PROCEDURES FOR

DEVELOPMENTAL DYSPRAXIA

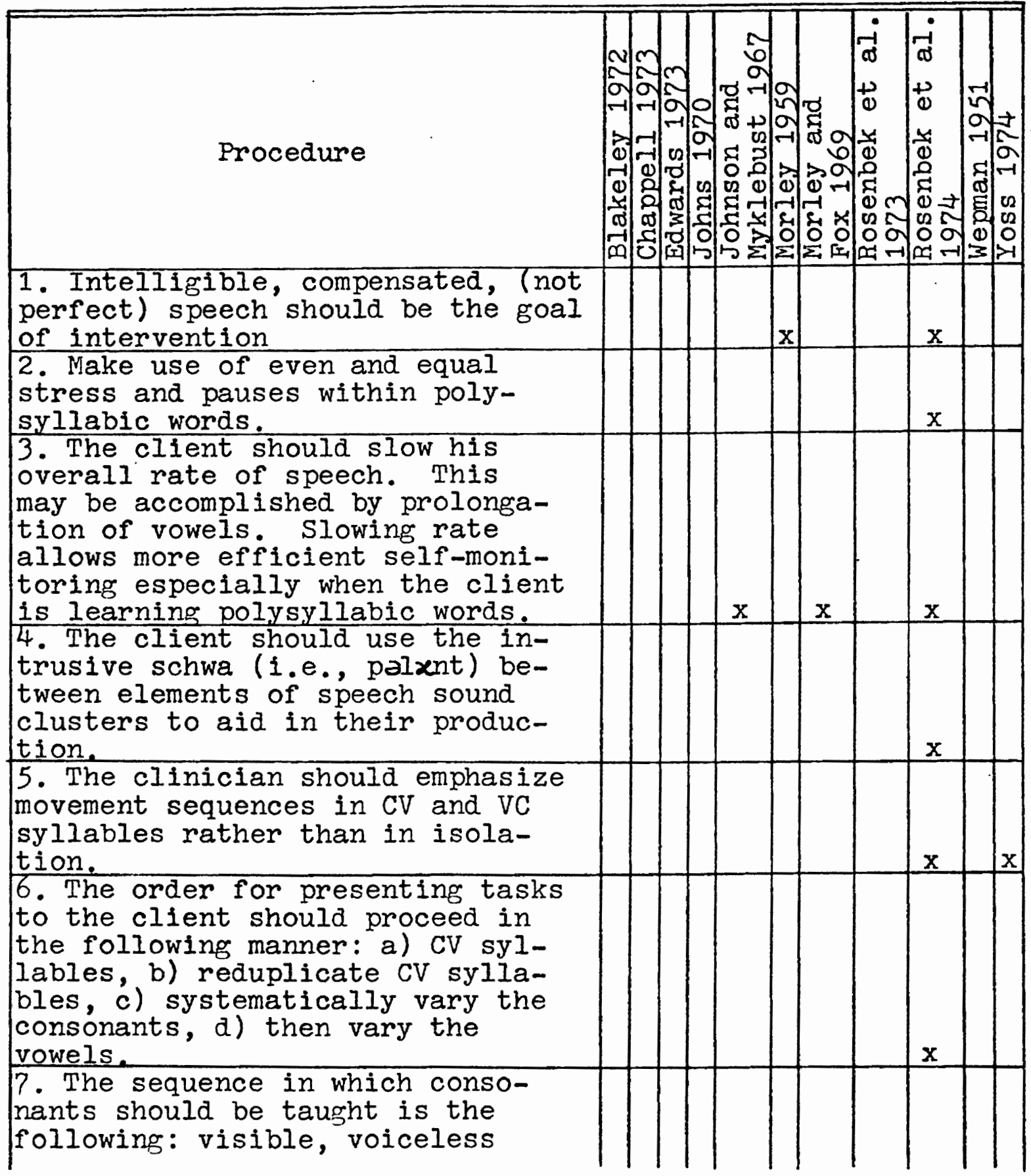




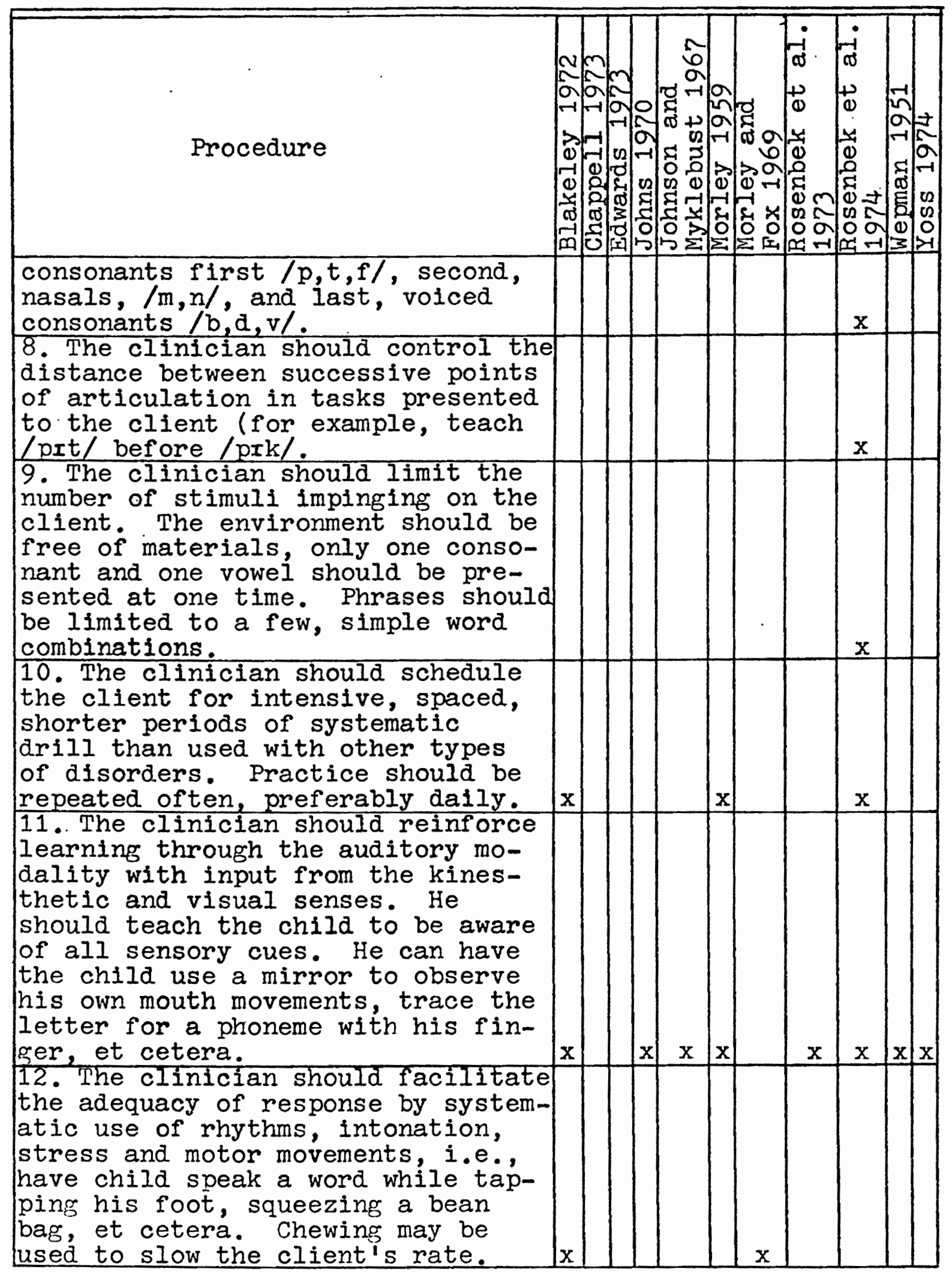




\begin{tabular}{|c|c|c|c|c|c|c|c|c|c|}
\hline Procedure & & & & 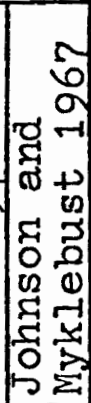 & & 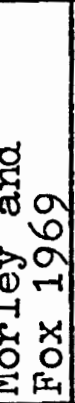 & 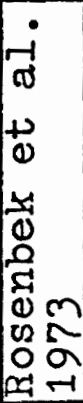 & 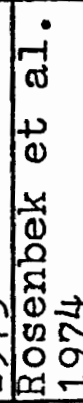 & \\
\hline $\begin{array}{l}\text { 13. The order for presenting tasks } \\
\text { to the client should preceed in the } \\
\text { following manner a) the sound is } \\
\text { first taught in isolation, b) cV } \\
\text { syllables should be next, c) the } \\
\text { sound should next be taught in non- } \\
\text { sense syllables of increasing } \\
\text { length, d) lastly, the sound should } \\
\text { be incorporated into meaningful } \\
\text { linguistic units. }\end{array}$ & & & & & & $\mathrm{x}$ & & & \\
\hline $\begin{array}{l}\text { 14. The clinician should work as } \\
\text { quickly as possible toward helping } \\
\text { the client produce functional mean- } \\
\text { ingful utterances. }\end{array}$ & $\mathrm{x}$ & $x$ & & $x$ & & & & & $\mathrm{x}$ \\
\hline $\begin{array}{l}\text { 15. The clinician should select } \\
\text { sounds and movements for work first } \\
\text { which are visible on the lips. }\end{array}$ & & & & $\mathbf{x}$ & & & & & \\
\hline $\begin{array}{l}\text { 16. The clinician should use read- } \\
\text { ing or written instruction, or } \\
\text { written symbols where this will } \\
\text { help. }\end{array}$ & $x$ & & & $\mathrm{x}$ & & & & & \\
\hline $\begin{array}{l}17 \text { The clinician should teach pro- } \\
\text { prioceptive neuromuscular facili- } \\
\text { tation; he should strengthen cor- } \\
\text { rectly produced motor patterns } \\
\text { He may actually move the child is } \\
\text { articulators for him if this helps } \\
\text { in producing correct sequencing. }\end{array}$ & $x \mid$ & $x \mid x$ & $x|x|$ & $\mathrm{x}$ & & & & & $x$ \\
\hline $\begin{array}{l}\text { 18. The clinician should explore } \\
\text { the child's intact modalities and } \\
\text { direct intervention through them. }\end{array}$ & & $\mathrm{x}$ & & & & & $\mathrm{x}$ & & \\
\hline $\begin{array}{l}\text { 19. The clinician may find it helps } \\
\text { to provide verbal instruction to } \\
\text { the child about where to place his } \\
\text { articulators. }\end{array}$ & & $\mathrm{x}$ & $\mathrm{x}$ & $\mathrm{x}$ & & & & & \\
\hline $\begin{array}{l}20 \text { The clinician should begin with } \\
\text { individual drill on isolated target } \\
\text { phonemes. }\end{array}$ & & $\mathrm{x}$ & & & & $\mathrm{x}$ & & & \\
\hline $\begin{array}{l}\text { 21. It may help the child in pro- } \\
\text { duction of some sounds if he moves } \\
\text { his articulators with his fingers. }\end{array}$ & & & & & & & & & \\
\hline
\end{tabular}




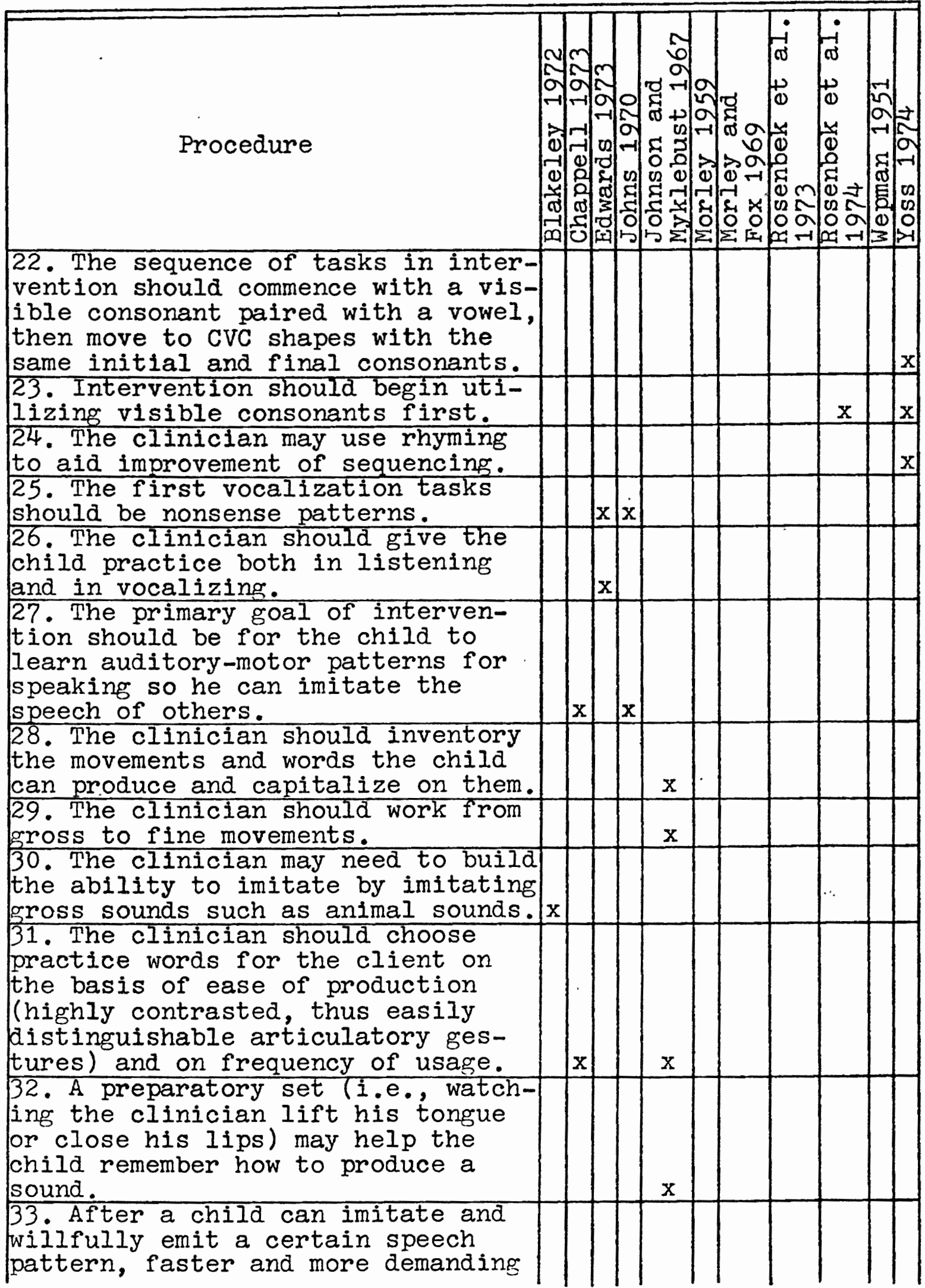




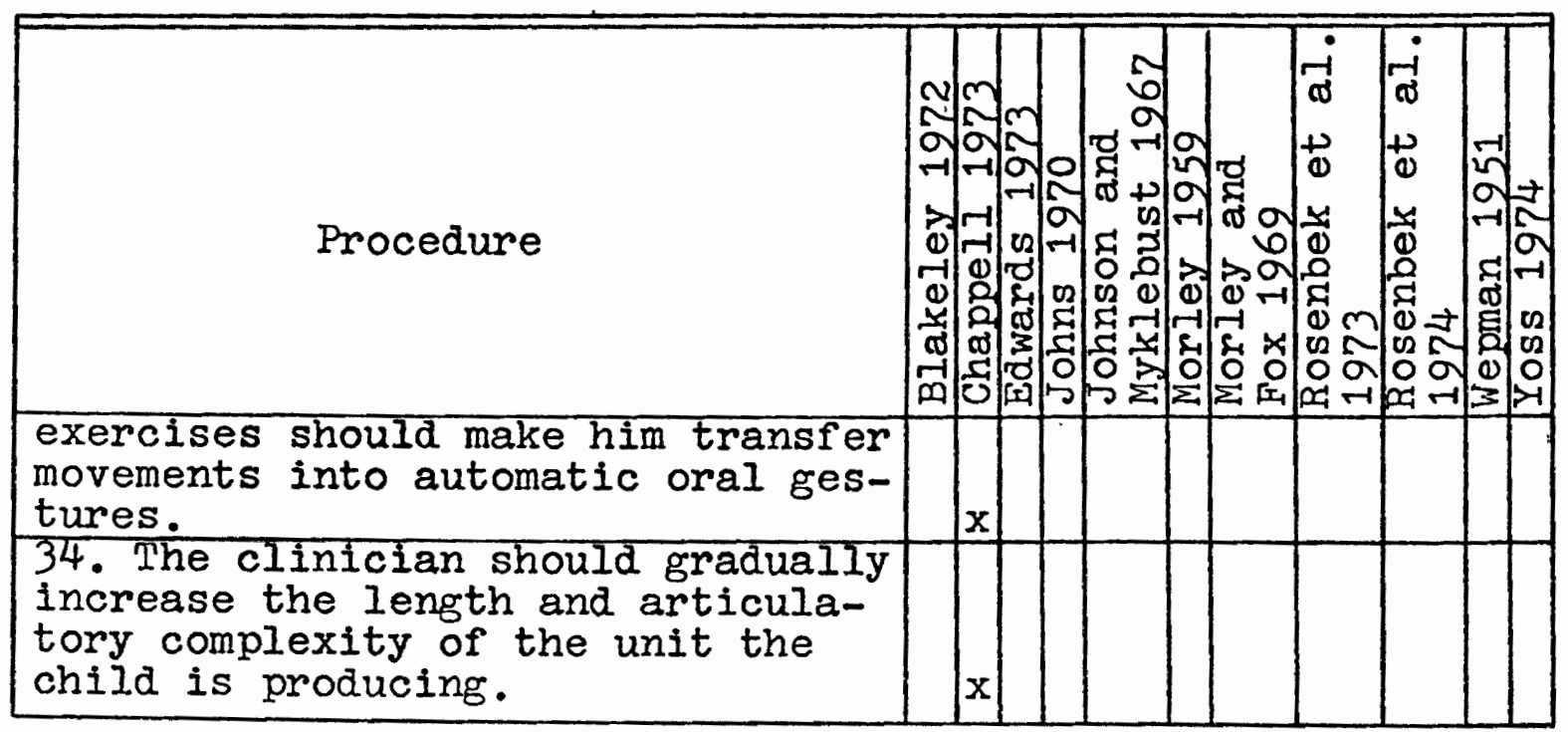




\section{APPENDIX D}

\section{DESCRIPTORS USED IN LOCATION}

OF PRE-DIAGNOSED DYSPRAXICS

1. General volitional control problems for the oral structures.

2. The more syllables per utterance, the greater the chance of articulation errors. Also, more articulation errors are present in polysyllabic words.

3. Immature or deviant use of syntactical structures is present, such as: incorrect verb usage, incorrect pluralization, inappropriate pronoun usage, omission of words (articles, prepositions, and/or modifiers), omission of word endings.

4. Verbal Ianguage expression skills are delayed or deviant.

5. Verbal sequencing skills are slow or deviant, particularly in repetition of three-syllable phrases such as puh-tuh-kuh.

6. Poor speech intelligibility ( $50 \%$ or less).

7. Multiple articulation errors in consonants including: omissions, substitutions, and distortions.

8. Inconsistency in articulation pattern - including articulation error pattern.

9. Verbal language comprehension skills are within normal limits.

10. Child uses telegraphic speech pattern. 


\section{APPENDIX E}

\section{MODIFIED APRAXIA BATTERY}

Verbal Section:

Tests for Apraxia of Speech (Score with + or -)

General Instructions: "I am going to ask you to say some sounds, words, and sentences. Iisten very carefully and say just what I say. Are you ready?"

1. "Say these sounds and hold them for as long as you can."

a. "Say ah and hold it as long as you can."

b. "Say ee and hold it as long as you can."

c. "Say oo and hold it as long as you can."

2. "Now I want you to say some other sounds. This time say them as fast and as long as you can."

a. "Say puh-puh-puh-puh-puh-puh."

b. "Say tuh-tuh-tuh-tuh-tuh-tuh."

c. "Say kuh-kuh-kuh-kuh-kuh-kuh."

"Now, take the three sounds, puh, tuh, kuh, and put them together."

d. "Iike this, puh-țh-kuh-puh-tuh-kuh."

3. "Now I want you to say some words after I say them."

(Present each word once.)

a. "gingerbread"

b. "artillery"

c. "snowman" 

a. "impossibility"
e. "catastrophe"
f. "television"

4. "Say these words after I say them."

(Present each word once and let the client respond before going on to the next word.)

"thick"

a. "thicker"

b. "thickening"

"jab"

c. "jabber"

d. "jabbering"

"zip"

e. "zipper"

f. "zippering"

"please"

g. "pleasing"

h. "pleasingly"

5. "Say these words after I say them." (Present each word once.)
a. "judge"
b. "peep"
c. "sis"
d. "church"
e. "zoos" 
f. "lall"

g. "shush"

h. "coke"

i. "gag"

j. "dad"

Number of "initial" errors:

Number of "final" errors:

6. "Repeat these sentences after me."

(Present each sentence once. Repeat once if needed. Score each word in each sentence.)

a. "Please put the groceries $\overline{\text { in }}$ the refrigerator." TRANSCRIBE:

b. "Arthur was $\overline{\text { an }} \overline{\text { ozzy }}$, oiy sneak." TRA NSCR IBE :

c. "In the summer they sell vegetables." TRANSCRIBE:

d. "The valuable watch was missing." TRANSCRIBE:

e. "Tiphe shipwreck washed $\overline{\text { up }} \overline{\text { on }}$ the shore." TRANSCRIBE:

7. "Tell me what is happening in this picture. What is happening? What do you see?"

(Present any large picture with several types of action. Elicit seven spontaneous sentences. Transcribe all utterances.) 
8. "Now I want you to repeat your sentences for me." (Ask the examinee to repeat, one at a time, the sentences he produced spontaneously in Subtest 7 . Examiner presents orally from transcriptions made on Subtest 7. Transcribe all responses.)

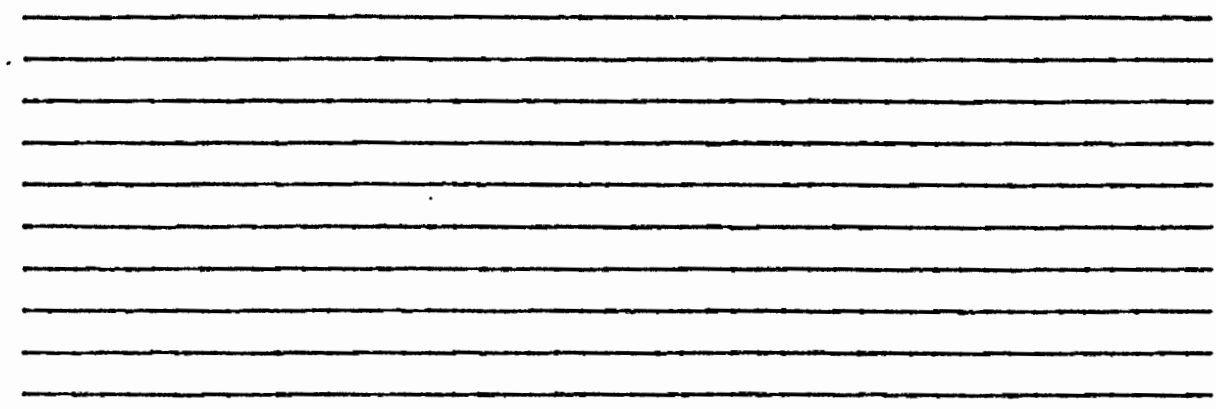

9. "I want you to do some counting for me."

a. "First, count from one to twenty."

one

two

three

four

five

six

seven

eight

nine

ten eleven

twelve

thirteen

fourteen

fifteen

sixteen

seventeen

eighteen

nineteen

twenty 
b. "Now, count backward from twenty to one."

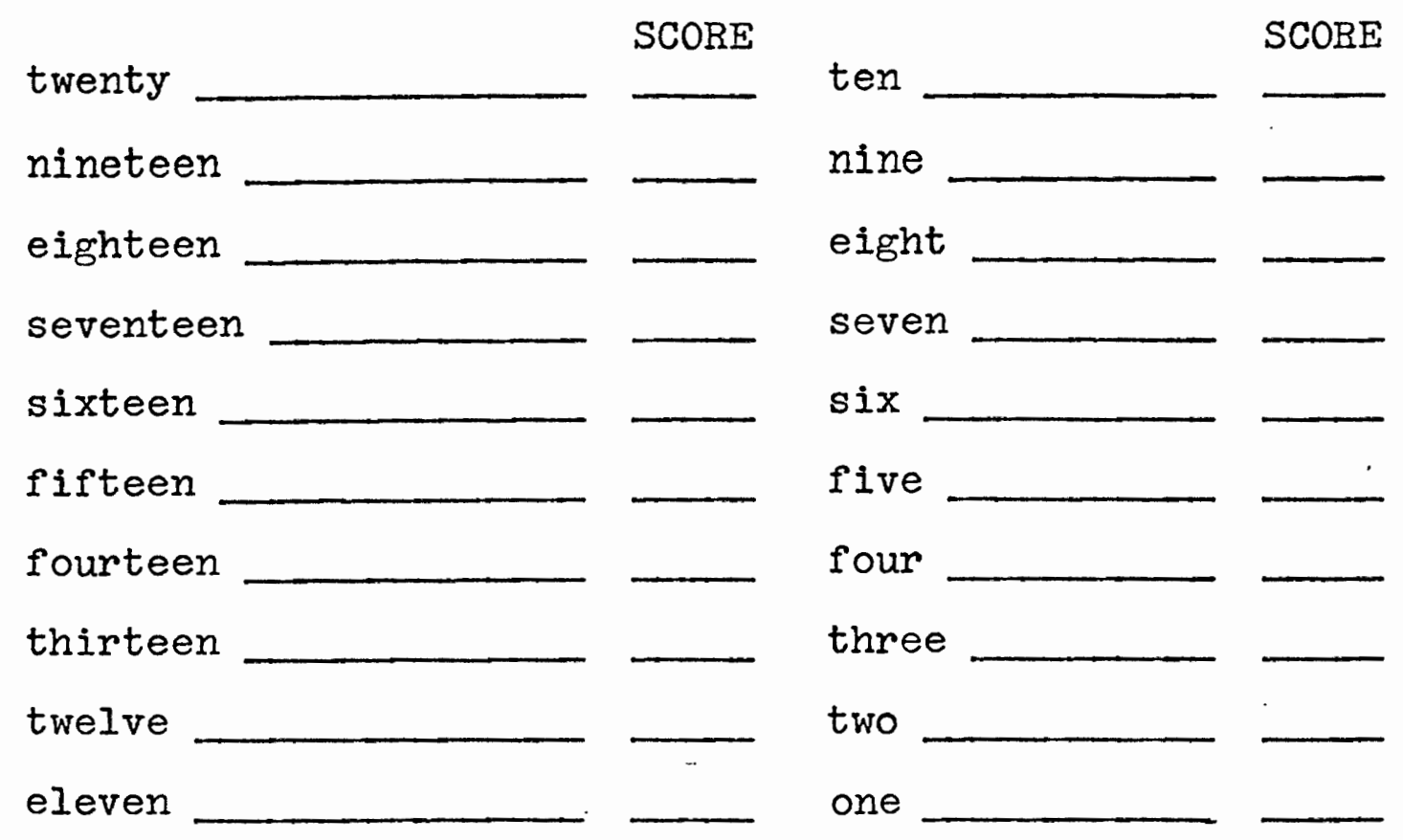

10. "I want you to say the days of the week for me."

a. "First, say the days of the week beginning with

Sunday
Monday
Tuesday
Wednesday
Thursday
Friday
Saturday

b. "Now say the days of the week backwards beginning with Sunday."

Sunday

Saturday

Friday 
Thursday

Wednesday

Tuesday

Monday

Nonverbal Section:

Tests for Oral Apraxia (Score with + or - )

General Instructions: "I am going to ask you to do some things with your mouth. First, I'll tell you what to do. If you don't know how to do what I ask, I'II show you what to do."

11a. (Use verbal command only initially. If do not get correct response, give visual model.)

Stick out your tongue.

Show me how you would whistle.

Touch the tip of your nose with your tongue.

Show me how you would kiss a baby.

Show me how your teeth chatter when you're cold.

Touch your chin with your tongue.

Wag your tongue from side to side.

Click or pop your tongue.

Puff out your cheeks.

Blow.

Clear your throat.

Show your teeth in a smile.

Lick your lips all the way around.

Bite your lower lip.

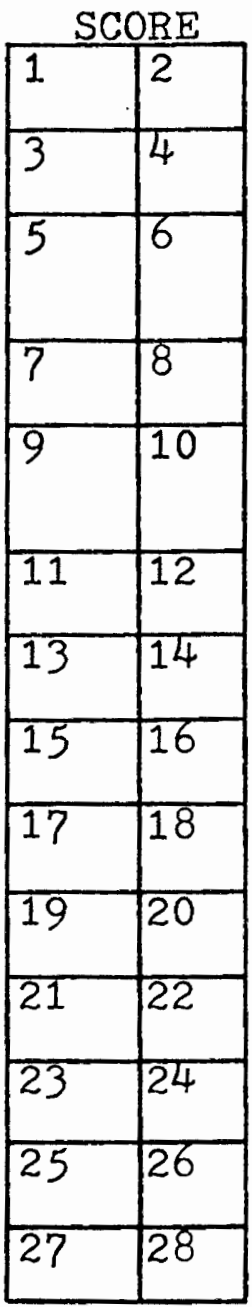


Comments :

11b. Directions: "Now we are going to put some of these movements together. Watch me and then do just what I have done."

(Allow two chances, repeat for child if does not produce sequence correctly after first demonstration.)

SCORE

Two-Item Sequencing Tasks:

Tongue protruded, lips in smile.

Lips puckered, tongue wag from side to side.

Teeth bite lower Iip, blow.

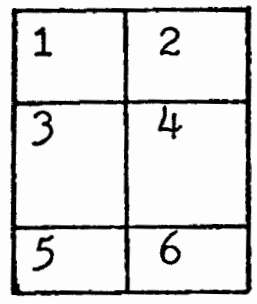

Three-Item Sequencing Tasks:

Click teeth (chatter), lick lips, clear throat.

Tip of tongue to nose, whistle, puff cheeks.

Kiss, click tongue, stick out tongue.

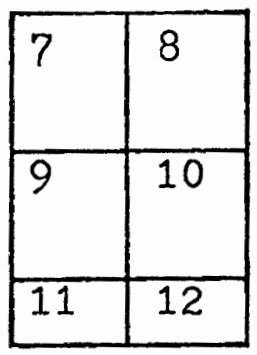

\section{Tests for Limb Apraxia}

General Instructions: "Now I want you to perform some movements with your arms and hands. Listen closely and do everything as completely and as weli as you can. If you do not know what to do, I will show you."

12. (Use verbal command only, initially. If do not get correct response, offer visual model.)

"Show how to salute."

"Show how to play an accordion."

"Wave goodbye."

\begin{tabular}{|l|l|}
\hline 1 & 2 \\
\hline 3 & 4 \\
\hline 5 & 6 \\
\hline
\end{tabular}


"Threaten someone with your hand." "Show that you are hungry."

"Thumb your nose at someone." "Show that something stinks." "Snap your finger."

"Show how to sharpen a pencil." "Indicate that someone is crazy."

SCORE

\begin{tabular}{|l|l|}
\hline 7 & 8 \\
\hline 9 & 10 \\
\hline 11 & 12 \\
\hline 13 & 14 \\
\hline 15 & 16 \\
\hline 17 & 18 \\
\hline 19 & 20 \\
\hline
\end{tabular}


APPENDIX F

SCORING CRITERIA FOR THE

MODIFIED APRAXIA BATTERY

Refer to Appendix $E$ for specific test items.

Subtest 1, Vowel Production: The examiner scored a plus (t) if each sound a) was sustained for three or more seconds and $b$ ) if on $1 a$ the child produced $/ a /$, if on $1 b$ the child produced / i/ and if on $1 c$ the child produced / $u /$. A minus ( - ) was scored if the child did not meet the above specifications.

Subtest 2, Diadochokinesis: Fletcher's (1962) norms were used to determine values to be classified as $(+)$ or $(-)$ scores. A $(+)$ was assigned to values which were at or better than one standard deviation below the mean. Scores one standard deviation below the mean were assigned a $(-)$.

Subtest 3, Multisyllabic Words: This item was assigned a (-) score if the child misarticulated an affricate, fricative or consonant cluster, or other consonant sound, omitted a syllable or transposed a sound or syllable. A (t) was assigned if no errors were made or if errors were other than those specified above.

Subtest 4, Words of Increasing Length: The one-syllable word in each group of increasing length was presented to the subject and transcribed, but was not scored either $(+)$ or 
(-). Items $4 a, 4 c, 4 e$ and $4 g$ (the two-syllable words) were assigned $a(-)$ if more errors or different errors were produced than were noted on the one-syllable word. A (t) was assigned if no errors or the same errors were produced as were noted in the one-syllable productions. Items $4 \mathrm{~b}, 4 \mathrm{~d}$, $4 \mathrm{f}$ and $4 \mathrm{~h}$ (the three-syllable words) were assigned $\mathrm{a}(-)$ if more errors or different errors were produced than were noted on $4 \mathrm{a}, 4 \mathrm{c}, 4 \mathrm{e}$ and $4 \mathrm{~g}$ respectively. A (t) was assigned if no errors or the same errors were produced as were noted in the two-syllable productions.

Subtest 5, Initial-Final Phoneme Comparison: A (-) was scored if production of the final sounds was "closer" to correct than production of the initial sound. "Closer" was defined as fewer distinctive feature errors. $A(t)$ was scored if initial and final sounds were produced the same or if the initial sound production was "closer" to correct than the final sound production.

Subtest 6, Sentences: Each word in each sentence was scored. A ( - ) was assigned if a phoneme or phonemes in a word were misarticulated, if syllables were omitted or if syllables or sounds were transposed. $A(t)$ was assigned if the word was produced correctly.

Subtest 7. Spontaneous Speech: Off-hand comments or profanity, slowed rate, even stress and even spacing were scored (-). A (t) was assigned if the child produced seven separate sentences with no prosodic changes, no off-hand comments or profanity. 
Subtest 8, Imitative Speech: The examiner instructed the child to repeat after him the sentences the child produced on subtest 7. A (-) was scored if there were more errors (i.e., misarticulations, syllable omissions, sound or syllable transpositions) than in the same sentences produced spontaneously in Subtest 7. A (t) was scored if there were the same number of errors or less on Subtest 8 than on the same sentences in subtest 7 .

Subtests 9 and 10, Automatic Speech: Numbers from 1-20 and the days of the week were first presented to the child in a forward pattern and productions were transcribed. The subject then produced 20-1 backwards and Sunday to Monday backwards. A (-) was scored if there were more errors (misarticulations, syllable omissions, sound or syllable transpositions) than on the same words produced in a forward pattern. A $(+)$ was assigned if there were the same number of errors or less errors on the backward production than on the forward production. If the child had to be prompted or needed a model to produce the sequences, these were scored in the same manner as productions without a model.

Subtest 11, Volitional Oral Movements: There were two parts to this item; 11a, Volitional Oral Movements, Isolated Tasks and 11b, Volitional Oral Movements, Sequencing Tasks. The odd numbered items in 11a were presented with auditory input only. A (-) was assigned if an important part of the movement was missing or if the movement was not produced. A ( + ) was assigned if the movement was produced with all 
portions present. The even numbered items were the same items as the odd numbered except they were presented with both visual and auditory input. The same scoring criteria were applied to both odd numbered items and to even numbered items. All 12 items in $11 \mathrm{~b}$ were presented with auditory and visual input. A (-) was assigned if a child produced the sequence with an important part missing, with any portion of the sequence out of order, or if the child did not produce the item. A $(t)$ was assigned if the child produced a properly sequenced item with correct movements.

Subtest 12, Limb Apraxia: The odd numbered items were presented with auditory input only. A (-) was scored if an important portion of the movement was missing or if the movement was not produced. A $(t)$ was scored if an item was produced completely. The even numbered items were presented with both auditory and visual input. The same scoring criteria were applied to both the even numbered and to the odd numbered items. 